\title{
Los palacios en la costa central durante los periodos tardíos: de Pachacamac al Inca
}

Les palais de la côte centrale durant les périodes récentes: de Pachacamac à l'Inca

Palaces on the central coast during the late periods: From Pachacamac to the Incal

Luis Felipe Villacorta 0.

\section{(2) OpenEdition Journals}

\section{Edición electrónica}

URL: http://journals.openedition.org/bifea/5119

DOI: 10.4000/bifea.5119

ISSN: 2076-5827

Editor

Institut Français d'Études Andines

Edición impresa

Fecha de publicación: 1 diciembre 2004

Paginación: 539-570

ISSN: 0303-7495

Referencia electrónica

Luis Felipe Villacorta O., « Los palacios en la costa central durante los periodos tardíos: de

Pachacamac al Inca », Bulletin de l'Institut français d'études andines [En línea], 33 (3) | 2004, Publicado el 08 diciembre 2004, consultado el 01 diciembre 2020. URL : http://journals.openedition.org/bifea/5119 ; DOI : https://doi.org/10.4000/bifea.5119

\section{c)}

Les contenus du Bulletin de l'Institut français d'études andines sont mis à disposition selon les termes de la licence Creative Commons Attribution - Pas d'Utilisation Commerciale - Pas de Modification 4.0 International. 
Bull. Inst. fr. études andines

2004, 33 (3): 539-570

\title{
LOS PALACIOS EN LA COSTA CENTRAL DURANTE LOS PERIODOS TARDÍOS: DE PACHACAMAC AL INCA
}

\author{
Luis Felipe VILLACORTA O.
}

\section{Resumen}

Recientes estudios para la costa central del Perú han evidenciado que durante el periodo Intermedio Tardío (S. XI a XV d.C.) la arquitectura del poder estuvo íntimamente ligada a un tipo particular de edificio: la residencia de elite o palacio. Las evidencias también indican que luego de la ocupación Inca de la misma región (S. XV), esta variedad de edificio conservó su vigencia como símbolo distintivo del poder político de las elites gobernantes (v.g. curacas). La persistencia de los palacios de tradición local como referentes del ordenamiento político de la llamada provincia inca de Pachacamac — al menos en la parte correspondiente al río Rímac- pone en evidencia un tema siempre actual en la discusión arqueológica: ¿cuáles fueron las características de la dominación política resultado de la ocupación inca de esta parte del Tahuantinsuyo? y ¿cuál fue la reacción de las elites locales ante el nuevo orden representado por este acontecimiento?

El presente artículo desarrolla este tema a partir de la definición de los atributos formales de los palacios, la descripción y uso de los artefactos asociados a los mismos, así como del análisis de las fuentes históricas que dan cuenta de las características particulares de la sociedad prehispánica tardía de la Costa Central.

Palabras claves: Monumental, palacio o residencia de elite, chaupiyunga, ushnu, inca.

\section{LES PALAIS DE LA CÔTE CENTRALE DURANT LES PÉRIODES RÉCENTES : DE PACHACAMAC À L'INCA}

\section{Résumé}

Des études récentes portant sur la côte centrale du Pérou ont mis en évidence le fait que durant la période Intermédiaire récent (XIe au XVe s. dne) l'architecture reliée au pouvoir était étroitement liée à un type particulier d'édifice : la résidence d'élite ou palais. Les données indiquent également que durant l'occupation inca dans la même région (15-16e siècles), ce type de bâtiment conserve toute son importance en tant que symbole spécifique du pouvoir politique des élites gouvernantes (c'est-à-dire les curacas). La persistance des palais de tradition locale comme référents de l'organisation politique de ce que l'on appelle la province inca de Pachacamac

* Director del Museo Raimondi - Lima. Miembro ordinario del Instituto Riva Agüero - PUCP. E.mail:1fvillac@pucp.edu.pe 
- tout du moins dans la zone correspondant au fleuve Rimac — met en evidence un thème toujours d'actualité dans le débat archéologique : quelles furent les caractéristiques du contrôle politique résultant de l'occupation inca dans cette partie du Tahuantinsuyu ?Quelle fut la reaction des élites locales face à l'ordre nouveau issu de la conquête ?

Cet article développe ce thème à partir de la définition des attributs formels des palais, la description et l'usage des artefacts associés à ceux-ci, ainsi que l'analyse des sources historiques qui rendent compte des caractéristiques particulières de la société préhispanique récente de la côte centrale.

Mots clés Monumental, palais ou résidence d'élite, chaupiyunga, ushnu, inca.

\title{
PALACES ON THE CENTRAL COAST DURING THE LATE PERIODS: FROM PACHACAMAC TO THE INCA
}

\begin{abstract}
Recent studies on the central coast of Peru have shown that during the Late Intermediate Period (11th to 15 th centuries A.D.) the architecture of power was closely linked to a certain type of building: an elite residence or palace. The evidence also indicates that after the Inca occupation of the above-mentioned region (15th century) this kind of building retained its effectiveness as a distinctive symbol of the political power of the governing elites, i.e. the curacas. The fact that local-style palaces continued to exist as referents of the political ordering of the so-called Inca province of Pachacamac (at least in the Rimac area), throws light on a topic that is still current in archaeological debate: What were the characteristics of the political domination that resulted from the Inca occupation of this corner of Tawantinsuyu? And what was the reaction of the local elites when faced with the new order that arose from this event? The present article develops this topic via the definition of the formal attributes of palaces, their description and the use of artefacts associated with them, as well as the analysis of historical sources that document the particular features of late pre-Hispanic society on the central coast.
\end{abstract}

Key words: Monumental, palace or elite residence, chaupiyunga, ushnu, Inca.

\section{INTRODUCCIÓN}

El curso inferior de la cuenca del Rímac fue el más importante y extenso del sistema de valles de Lima, integrado además por los tramos bajos de los ríos Chillón y Lurín. En su conjunto, los valles bajos de estas tres cuencas conformaron prácticamente una unidad agropecuaria e hidráulica conocida tradicionalmente como "Costa Central" (ver p.e. Rostworowski, 1978; 1989; Bonavia, 1991; Eeckhout, 1999; 2000; Cornejo, 2000; etc.). La importancia estratégica de la cuenca del Rímac, vislumbrada a partir de su mayor capacidad productiva, se manifiesta en su especial configuración geográfica la que favorece en su curso inferior o bajo un amplio abanico aluvial. Esta circunstancia natural fue potenciada al máximo por las poblaciones prehispánicas mediante el desarrollo de una impresionante red de canales, muchos de los cuales tienen sus nacientes en la parte del cuello del valle, a la altura de las estribaciones andinas o valle medio bajo del Rímac (Rostworowski, 1978; Villacorta, 2001).

El desarrollo de la red de canales significó en la práctica la integración a la dimensión económica costeña de una zona con características medioambientales 
particulares: la chaupiyunga (p.e. Rostworowski, 1978; 1981). Esta situación permitió a los grupos costeños tener tanto el crucial control de la red hidráulica que abastecía los fértiles campos del valle bajo como acceder a productos agropecuarios viables solo en este tipo de ecosistema (v.g. chaupiyunga), los que además gozaban de alta estimación en el mundo andino (p.e. ají y coca costeña).

Estas condiciones, sumadas a los cambios de paradigmas que rigieron la región luego del Horizonte Medio, se vieron reflejadas en un desarrollo arquitectónico poco conocido e investigado hasta la fecha en este tramo del valle del Rímac, el mismo que en los periodos tardíos alcanzó su síntesis en una variedad de edificación: la residencia de elite o palacio. El presente estudio reseña las características principales de este tipo de edificación, las particularidades que tuvo en el valle medio bajo del Rímac, así como las dimensiones de su acción teniendo en cuenta los cambios en las relaciones de poder representados en primera instancia por la hegemonía regional del oráculo de Pachacamac y luego durante la ocupación Inca de la "Costa Central".

\section{EL ÁREA DE ESTUDIO: GEOGRAFÍA, MEDIO AMBIENTE Y PAISAJE CULTURAL}

El Rímac es uno de los ríos de mayor caudal e importancia en la costa peruana. Su cuenca tiene una extensión aproximada de $3500 \mathrm{Km}$ discurriendo en dirección Sudeste-Noroeste a lo largo de 140 kilómetros de recorrido (IGM, 1989: 361). Sus nacientes se ubican en la cordillera occidental de los Andes, en el nevado de Ticlio, a una altura cercana a los 5000 m.s.n.m. El origen de sus aguas es glacio-níveo-pluvial, es decir se forman de la fusión de los deshielos de glaciales y nieves de las altas cumbres andinas, así como por las lluvias estacionales del verano austral. Por esta razón, y como la mayoría de ríos de la costa, su régimen de aguas es torrencial o irregular, con grandes avenidas durante la época de lluvias y una fuerte reducción del caudal durante el periodo de estiaje. A pesar de ello, el Rímac es uno de los pocos ríos de la costa que mantiene caudal durante todo el año (p.e. Tumbes, Chira, Santa, Pativilca, Cañete, entre otros pocos ríos costeros).

El presente estudio se realizó en un tramo de 14 kilómetros de extensión correspondiente al valle medio bajo de la cuenca del Rímac, área que tiene como extremos a los sitios arqueológicos de la Puruchuca (270 m.s.n.m.) y Huaycán de Pariachi (575 m.s.n.m.; ver Villacorta, 2001; Fig. 1). Este sector del Rímac presenta características geográficas particulares; así es evidente comprobar que el río en su recorrido a la altura de Ricardo Palma, Chosica y Chaclacayo es torrentoso debido a lo estrecho de su cauce. Es solamente a partir de la zona de Huaycán y Carapongo que esta situación experimenta un cambio sensible. La superficie aluvial se amplía considerablemente, aparecen en ambas márgenes grandes quebradas tributarias, cuyos conos de deyección forman en su parte baja importantes extensiones de superficie cultivable (p.e. cuenca de la quebrada Huaycoloro, Huachipa, Pedreros, Santa Clara, Monterrey, Barbadillo, Pariachi, etc.). Además el cauce es más amplio, la pendiente es mucho más suave y por lo tanto el discurrir de sus aguas es más pausado, observándose un considerable ensanchamiento en el espejo de agua, lo que favorece las filtraciones y la alimentación de la napa freática. 


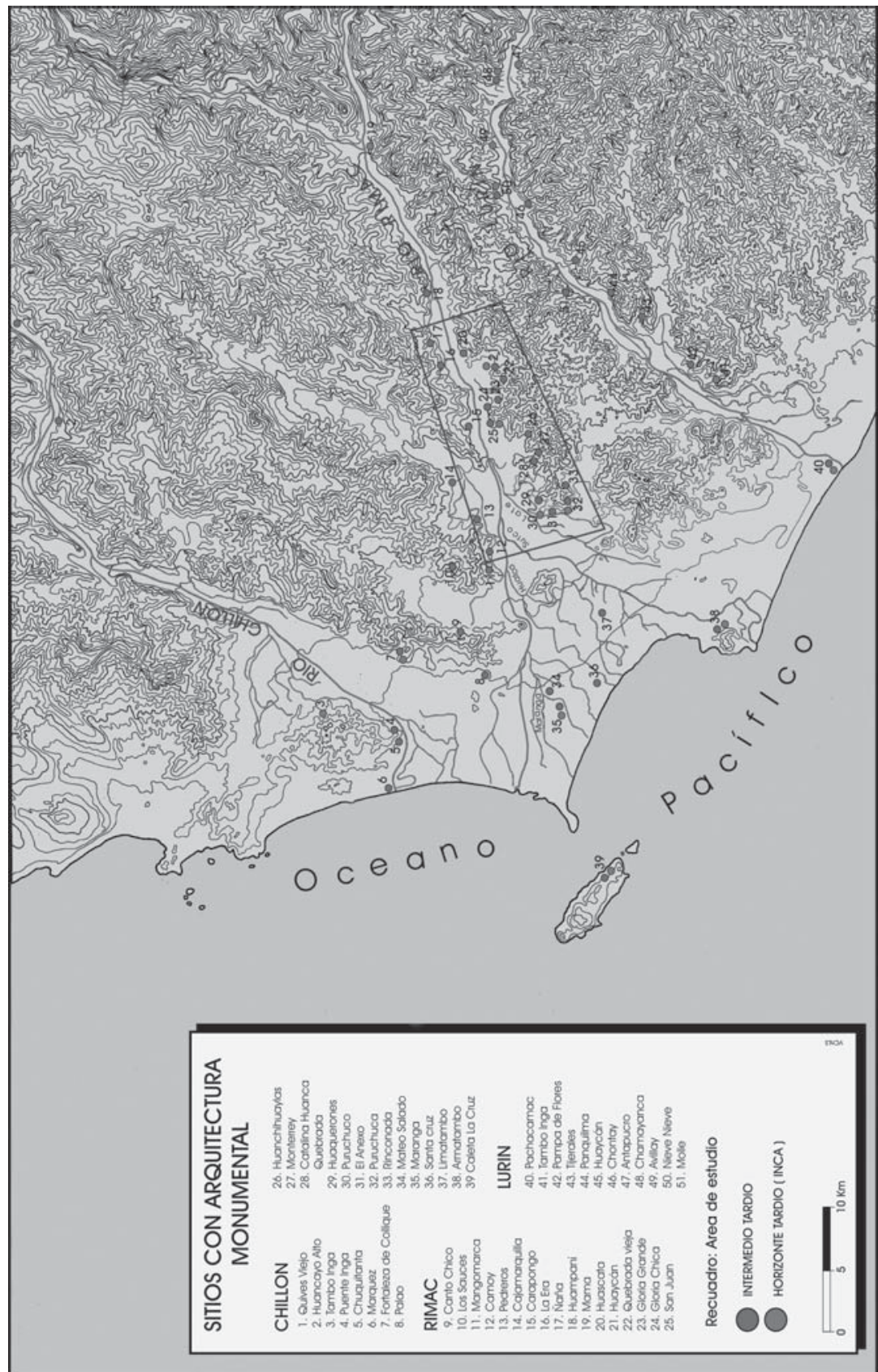

 
Un rasgo interesante a destacar es que este tramo de la cuenca posee una alta productividad agrícola, tanto por la abundancia de agua superficial y subterránea, como por las avenidas estacionales del Rímac, las que enriquecen con nutrientes el contenido de las aguas (limos), renovando la capacidad productiva de los suelos. Estas condiciones han hecho posible que una hectárea del valle medio bajo del Rímac (entre Puruchuco y Huaycán) posea estándares de productividad similares a aquellos terrenos ubicados en el valle bajo, el área más rica de toda la cuenca del río (ONERN, 1975; ver Fig. 1).

Desde el punto de vista mediambiental el valle bajo del río Rímac forma parte del desierto del Pacífico, cuyo clima se caracteriza por ser cálido en el verano y templado en el invierno, alcanzado en esta última temporada índices de humedad relativa de hasta $100 \%$ (Brack Egg, 1996: 24-25). Estas condiciones se pueden generalizar para toda la faja costera del Perú desde Trujillo hasta Tacna, especialmente en el área contigua al litoral Pacífico y por un ancho promedio de $20 \mathrm{~km}$ hasta las nacientes de las estribaciones de la cordillera de los Andes. Esta ecorregión ha sido denonimada como Chala o Costa en la famosa clasificación de Pulgar Vidal (1996: 33 - 59). Según este autor la región Chala o Costa "se extiende desde la orilla del mar, a cero metros, tierra adentro hasta dónde la pendiente alcanza los 500 metros" (Pulgar Vidal, 1996: 34).

Al respecto debemos indicar que estudios históricos han rescatado la voz indígena de "chaupiyunga" como el término que hace referencia al tramo de los ríos de la vertiente occidental cuyo clima es seco y soleado la mayor parte del año, donde no existen las pronunciadas fluctuaciones de temperatura entre el día y la noche que caracterizan a otras regiones altoandinas y que a la vez se encuentra fuera del alcance de las neblinas propias de la faja de territorio contiguo al litoral Pacífico. Estas especiales condiciones climáticas hicieron prosperar ciertos cultivos de valor económico y simbólico importante para el poblador prehispánico, especialmente el ají y la apreciada variedad de coca costeña (capsicum sp. y erythroxylum sp. respectivamente; ver Rostworowski, 1989: 239-261). A partir de las mismas fuentes se ha establecido que el rango de altitud que define esta área oscila entre los 200 a 1200 m.s.n.m. Es decir que desde el punto de vista ecológico y cultural, el tramo del Rímac donde realizamos nuestras investigaciones corresponde a lo que en tiempos prehispánicos era conocido por los indígenas costeños como chaupiyunga (Rostworowski, 1989: 246) (1).

Esta observación tiene un interesante correlato en la toponimia con la que se conoce a esta región del valle medio bajo del Rímac, ya que sabemos que la zona que actualmente conocemos con el nombre de Puruchuco es resultado de la composición de dos vocablos de origen quechua: puca y rucha (o algunas voces semejantes) (2), lo que traducido al español y debidamente estructurado significaría “ají rojo”. La importancia de esta toponimia se basa en que mediante ella se hace referencia expresa a las

(1) Los trabajos de Pulgar Vidal sobre las ecorregiones de los Andes hacen marcado énfasis en conceptos tradicionales, de evidente raíz prehispánica, los que influenciaron decididamente en la organizan de su clasificación. Por razones que desconocemos no incluye el término que propone Rostworowski (v.g. Chaupiyunga). En todo caso, el aporte de la investigadora puede considerarse una contribución que enriquece la perspectiva del primero.

(2) María Rostworowski, comunicación personal. Ver discusión sobre el término y otros posibles significados en Jiménez Borja, 1988: 7-8. 
características medioambientales de la zona (cálida y soleada), las que son propicias para la siembra de esta variedad de cultivo (v.g. ají) como otros que pudieron crecer en condiciones semejantes (p.e. coca) (3).

Esta condición medioambiental adquiere una connotación especial si tenemos en cuenta uno de los testimonios arqueológicos más impresionantes del valle bajo del Rímac: su compleja y eficiente red de canales de regadío (Rostworowski, 1978). Este sistema hidráulico tiene sus nacientes en el denominado valle medio bajo, lo que pone en evidencia que desde el momento de la construcción de esta red (p.e. finales del intermedio tardío; Shimada, 1994: 122-123), se formalizó una estrecha relación con el curso inferior de la cuenca del Rímac. Justamente importantes canales de la margen izquierda del Rímac como los ramales de Ate o Surco tienen sus nacientes a la altura de Santa Clara y las Salinas respectivamente (Cerdán \& Pontero, 1793; ver Fig. 1).

Resulta evidente que la implementación de esta amplia red hidráulica permitió a los grupos costeños aumentar su frontera agrícola y elevar la productividad de sus campos. Ello les otorgó una gran ventaja con respecto a los grupos del valle medio y alto (la mayor parte de toda la cuenca), donde la gran mayoría de áreas de cultivo estaba sometida al régimen de secano, lo que las hizo más vulnerables ante cualquier desarreglo climático o desastre natural. A su vez, la ubicación de las bocatomas de estos importantes canales, en un nicho medioambiental distinto al del litoral vecino, permitió que los grupos costeros gozaran de un acceso directo a importantes recursos agrícolas de alta estima social, como el ají y la coca costeña.

\section{HACIA UNA DEFINICIÓN DE CONCEPTOS: ARQUITECTURA MONUMENTAL Y "PALACIOS O RESIDENCIAS DE ELITE”}

El presente artículo pretende abordar lo que desde nuestra perspectiva representa la manifestación más significativa de la arquitetura monumental de los periodos tardíos del valle del Rímac: el palacio o residencia de elite (4). Sin embargo, debemos admitir que antes de entrar en detalles sobre las características de lo que denominamos "palacio", es necesario precisar lo qué entendemos por "monumental". Quizás la mayor riqueza de este término es la sensación imprecisa que deja, lo que le otorga una gran versatilidad, ajustándose tanto a las diversas formas y escalas de la cultura material como de la complejidad social. La ejecución de una obra de características monumentales no se define a partir del tamaño o escala del edificio, sino por la magnitud de la inversión social que la comunidad que la ejecuta está en posibilidad de realizar sin afectar su propia estabilidad. En ese sentido compartimos las ideas de Bruce Trigger quien define la monumentalidad de la manera siguiente:

"Its principal defining feature is that the scale and elaboration exceed the requirements of any practical functions that a building is intended to perform" (Trigger, 1990: 119).

(3) La Dra. María Rostworowski fue testigo hace ya muchos años de plantas de coca cultivadas junto con árboles de pacae en una chacra en la quebrada de la "Era", esto es en la margen derecha del Rímac, frente a Huaycán de Pariachi (comunicación personal).

(4) En el caso del presente estudio, y ante el estado actual de nuestras investigaciones, utilizamos ambos términos como sinónimos. 
Esta breve definición enfatiza la escala relativa de la construcción, resultando suficientemente clara para percibir lo que la magnitud particular de lo monumental representa para una sociedad determinada, y en la que el concepto se entiende por el grado de inversión social manifiesto en sus edificios, particularmente aquellos de carácter público. Ellos son testimonio de las capacidades tecnológicas (elementos y técnicas constructivas) y sociopolíticas (organización y ejecución del proyecto monumental) de una sociedad en particular. Sin embargo, ¿cuál es el estímulo que motiva la inversión, aparentemente innecesaria, en la construcción de un edificio cuya magnitud excede las necesidades prácticas que satisface, cualquiera que sea su función?

La respuesta está en el concepto mismo de "monumento", uno de cuyos significados evoca la memoria o el recuerdo. Así, cada obra de escala monumental pretende perpetuar un mensaje (Moore, 1996; Wason, 1996). El espacio monumental no debe ser entendido sólo como la manifestación empírica de las capacidades coercitivas y productivas de los grupos que le dan origen, sino como un espacio que también simboliza diversos aspectos de la cosmología e ideología de la comunidad. Así por ejemplo, puede ser la residencia de los ancestros, representar el orden y la estructura social o simbolizar el calendario de las actividades rituales (véase Rapoport, 1969; Anders, 1986; Salomon, 1995; entre otros). Las obras de escala monumental son el reflejo del poder de la comunidad, y en muchos casos están estrechamente ligadas a las atribuciones exclusivas de las elites gobernantes. Jerry Moore afirma lo siguiente acerca de la relación entre arquitectura y poder en los Andes:

"Monuments are public, although the public may range from few families to a nation-state of millions. Monuments are structures designed to be recognized, expressed by their scale or elaboration, even though their meaning may not be understood by all members of a society" (Moore, 1996: 92).

Siguiendo la línea de nuestra investigación, un monumento tiene entonces como característica intrínseca un carácter o componente público que simboliza un mensaje de poder, al margen de cualquiera que haya sido su función primaria (religiosa, residencial, administrativa o militar).

El otro concepto que utilizamos es "residencia de elite o palacio", el que nos plantea como reto esclarecer y caracterizar la "función" de los edificios de nuestra muestra a los que definimos con este término. Ante la imposibilidad de realizar excavaciones arqueológicas y debido a la escasez de publicaciones sobre los trabajos de campo previos en la zona, estamos limitados a inferir la función a partir de los atributos de la configuración arquitectónica, la misma que además nos brinda criterios sobre cronología relativa e interpretación de los patrones de organización espacial.

Asimismo hemos asumido tácitamente que este tipo de edificación (v.g. los palacios) tendría características monumentales. Ello se debe a que en las sociedades fuertemente estratificadas, como la descrita en las fuentes etnohistóricas para la costa central (p.e. Cieza de León, 1986[1553]; Cobo, 1964[1639]), la residencia de un gobernante representa una manifestación de "pretensiones" públicas (su arquitectura destaca de manera particular), un lugar de toma de decisiones (atribución administrativa) y la materialización del poder de sus ocupantes. De este modo asumimos que la 
"residencia de elite o palacio" difiere de otro tipo de construcciones que cumplen la misma función residencial (casas de los comunes), y también de aquellos edificios que fueron hechos para satisfacer otras necesidades públicas (mausoleos — chullpas-, edificios religiosos, construcciones militares, etc.).

Antes de caracterizar desde el punto de vista arquitectónico a una residencia de elite o palacio, es necesario precisar el significado de este término y — sobretodocuáles son las funciones de esta variedad de edificación, tanto desde el punto de vista de la teoría antropológica, como de la propia experiencia de la arqueología andina.

Al respecto, Paul K. Wason (1996: 141) sostiene que las residencias de elite se caracterizan por disponer de un espacio más amplio que el resto de viviendas de la comunidad que cumplen con el mismo propósito doméstico. Esta realidad se fundamenta en el hecho de que esta "casa" es también el espacio donde se atiende a otros grupos distintos al de la familia del líder (v.g. la comunidad). Así, muchas de las facilidades que justifican esta amplitud encuentran su explicación en la necesidad del líder por controlar y atender aspectos como el almacenamiento de excedentes, la manufactura de objetos suntuarios, o la organización de la redistribución y las redes de intercambio. La centralización de todas estas actividades y recursos fue privilegio exclusivo del líder y fundamento de su status social. De esta manera, los rasgos descritos permiten vislumbrar a la residencia de elite como una edificación que puede ser reconocida por:

a) sus características físicas;

b) su tamaño "monumental";

c) su ubicación prominente;

d) el uso de elementos y técnicas constructivas particulares o "más elaboradas";

e) el diseño y construcción unitario de la obra;

f) por la asociación de múltiples componentes arquitectónicos formalmente diversos como parte del mismo espacio construido, donde es posible distinguir áreas públicas y otras reservadas.

De acuerdo con lo expuesto, se puede sostener que el diseño de los edificios en cuestión (v.g. palacios o residencia de elite), excede largamente a la sola función doméstica. Su complejidad se sustenta en la centralización de la toma de decisiones - exclusivas de sus ocupantes principales_-, que conciernen al control, transformación y administración de los recursos materiales e ideológicos de una sociedad determinada.

Pero ¿cómo es posible percibir en la arquitectura y desde la perspectiva arqueológica - aplicada para el caso andino- aquellos rasgos en la ubicación, construcción y configuración de los edificios que permitan atribuir funciones de control y administración, propias del "palacio o residencia de elite"? Al respecto, Mackey (1987: 126) realizó un interesante sumario en la que se pueden distinguir siete características principales:

a) un sector de vivienda para el administrador;

b) el control de otros asentamientos;

c) la administración de recursos naturales, especialmente tierras y agua;

d) el control de la fuerza de trabajo con objetivos económicos o militares;

e) colecta, almacenamiento y envío de bienes; 
f) realización de actividades ceremoniales y religiosas;

g) control de la producción manufacturera del Estado.

Los rasgos señalados por Mackey resumen diversos estudios hechos en distintas épocas y regiones de los Andes centrales; sin embargo, ellos no son excluyentes entre sí, ya que son el resultado del distinto énfasis que los investigadores han atribuido a sus trabajos. Muchos de estos resultados no han sido inferidos sobre la base de la problemática del presente trabajo (v.g., características de la residencia de elite o palacio). No obstante, se encuentran estrechamente ligados, debido a que forman parte de la misma discusión: las relaciones de poder en la sociedad a partir del control y administración de sus recursos, y una de sus manifestaciones empíricas, en este caso, la arquitectura.

Para los edificios que forman parte de la presente investigación, la atribución de las funciones señaladas en el listado previo solo tiene coherencia a partir de la identificación de aquellos componentes arquitectónicos recurrentes en su configuración, que finalmente los relacionan entre sí, otorgándoles no solo una identidad funcional, sino también, cultural (p.e. Ychsma, Inca, etc.).

Así, y para el caso de la Costa Central en particular, definir las características de la arquitectura local ha sido siempre un problema difícil de abordar para los arqueólogos especialistas en la problemática tardía. A pesar del registro de una cantidad importante de sitios en los valles del Chillón, Rímac y Lurín, con diversas expresiones monumentales, la discusión sobre la arquitectura tardía ha sido restringida a las formas presentes en Pachacamac, particularmente al tipo denominado "pirámide con rampa" (de ahora en adelante: PCR). Esta construcción representó por mucho tiempo el paradigma arquitectónico para la región, lo que limitó la discusión, al quedar excluidos de los análisis edificios contemporáneos no menos importantes pero de distintas características (p.e. Ravines, 1985; UNI-FORD, 1994; Eeckhout, 1999; Villacorta, 2001).

Las pirámides del valle medio bajo del Rímac, exhiben características particulares con respecto a las de Pachacamac (ver Fig. 2; Villacorta, 2001). La configuración de aquellas de Huaquerones y Monterrey ubicadas en el valle del "río hablador" se restringe, en cuanto a sus componentes arquitectónicos se refieren, al volumen principal, patio, rampas y depósitos; prescindiendo de los demás componentes registrados en las estructuras más elaboradas del santuario como los grandes depósitos (5), caminos epimurales, ingresos tortuosos o áreas compatibles con la actividad residencial (Paredes \& Franco, 1987). Es también evidente el propósito de minimizar intencionalmente la inversión en materiales y mano de obra, como en el caso de Huaquerones, donde se han aprovechado los desniveles de una estructura más antigua para la construcción de las pirámides de este complejo (6). Así, las pirámides del Rímac pueden considerarse manifestaciones simplificadas de sus símiles de Pachacamac (ver Fig. 3).

(5) La presencia de depósitos ha sido comprobada para la PCR 3 de Huaquerones; sin embargo las dimensiones de estos depósitos cuadrangulares no se pueden comparar con aquellos enormes de las PCR de Pachacamac o incluso con otras del mismo Rímac, como los registrados en el "palacio" o Conjunto Arquitectónico N 5 del complejo arqueológico de Huaycán de Pariachi.

(6) Probablemente de la cultura Lima. Observaciones de campo del autor. 


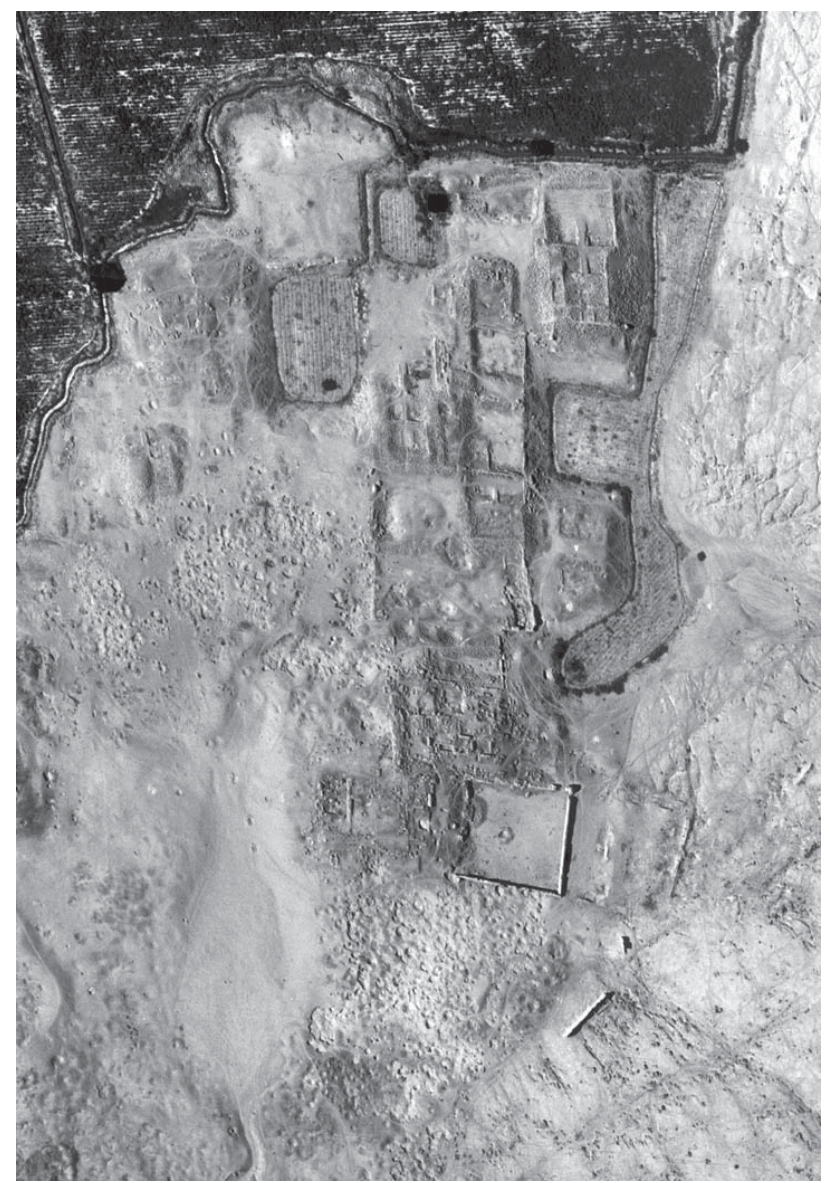

\section{Fig. 2 - Vista aérea de las PCR de Huaquerones (1944). Servicio Aerofotográfico Nacional.}

Es así que por la simplicidad del trazo de las PCR del Rímac, donde los patios son reducidos a espacios pequeños (7), los desniveles no son dramáticos y las plataformas son convertidas virtualmente en podios, lo que pone en relieve la intención de resaltar en su construcción solo sus atributos primarios o "canónicos", los que finalmente permiten reconocerlas como una misma variedad de edificio, y por lo tanto asumir a partir de la recurrencia de estos componentes arquitectónicos una función común a todos los edificios de este tipo. Debido a las evidencias disponibles es difícil establecer la naturaleza precisa de la función de las PCR. Eeckhout ha planteado que en el caso de Pachacamac representan palacios donde residía la casta señorial de los Ychsma, organizada en un sistema de sucesión dinástica (Eeckhout, 1999).

(7) En los casos extremos, dichos patios difícilmente albergaron más de cincuenta personas (p.e. PCR 4 PCR 5 de Huaquerones; Villacorta, 2001). 


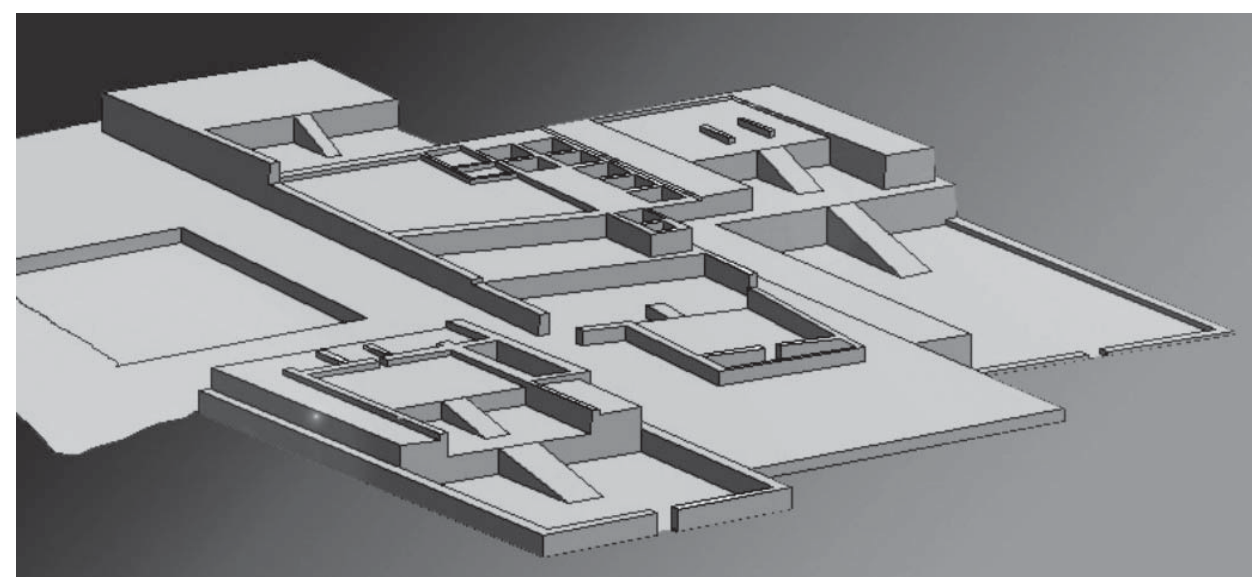

Fig. 3 - Vista de las PCR $N^{\circ} 1,2$ y 3 de Huaquerones.

Ante las características mencionadas es difícil sostener la posibilidad que los edificios identificados en el Rímac, sensiblemente menores a los de Pachacamac, puedan haber sido utilizados como palacios. Si ellos albergaron a manera de residencia a un curaca local, es evidente que el área que corresponde a esta función doméstica jamás fue considerada en el diseño del edificio, integrado solo por el patio, plataforma y, a lo más, algunos depósitos (Villacorta, 2001).

La reproducción o estandarización de los rasgos mínimos de las PCR tiene a nuestro juicio otras connotaciones que estarían relacionadas a funciones de índole religiosa y/o administrativa. Énfasis especial merece la "audiencia”, espacio público por excelencia de estos edificios y que esta integrado por la(s) terraza(s) y el patio unidos por la rampa (8). Este diseño favorece un escenario de ejercicio del poder, remitiéndonos al acto de presenciar/dirigir reuniones en un entorno físico que condiciona y acentúa una relación jerárquica (p.e. arriba y abajo; superior e inferior; pocos y muchos; etc.). Por la construcción sucesiva y recurrente de varios edificios de este tipo en un mismo asentamiento, los atributos públicos de su diseño y la ausencia de espacios residenciales, proponemos que las PCR corresponderían a estructuras de uso eventual y cíclico (Villacorta, 2001). Adelantando una opinión con respecto a su uso, consideramos que es posible vislumbrar que este modelo arquitectónico representó un escenario social

(8) Cabe indicar que el término "audiencia" es utilizado en el caso del Rímac para hacer referencia a la asociación de una terraza que domina un gran patio al interior de un mismo conjunto arquitectónico. Este componente arquitectónico es común a las PCR como a los palacios. Ellos son el espacio público por excelencia en ambos tipos de edificios, a los que se accede directamente desde el exterior por el único acceso que permite el muro perimétrico característico de estas construcciones (ver Villacorta, 2001). El uso de este término (audiencia) no debe confundirse con aquel que hace referencia a las estructuras en forma de "U" de las famosas ciudadelas de Chan Chan o los centros administrativos provinciales Chimú (ver p.e. Andrews, 1980; Cavallaro, 1997; etc.). En cuanto a su función, las audiencias del Rímac serían análogas a las grandes plazas o patios interiores de las ciudadelas Chimú, las que, coincidentemente, también están dominadas por una terraza. 
donde los curacas del Rímac asumían la dirección de los eventos derivados de las obligaciones locales que los vinculaban con el santuario de Pachacamac. El rango de obligaciones incluía el cultivo y procesamiento de los productos agropecuarios así como la elaboración de distintas manufacturas (cerámica, textiles, etc.). Estas labores eran realizadas por distintos grupos locales, siguiendo turnos y eran renovadas permanentemente al amparo y coordinación de esta variedad de estructuras. Las diferencias en su configuración (forma y tamaño) entre las de Lurín y el Rímac se explicarían a partir de las posibilidades sociales y económicas de sus promotores (p.e. disposición de mano de obra, uso de excedentes, etc.), como a restricciones derivadas del sistema político o religioso acordadas, impuestas o toleradas por Pachacamac. Si bien hasta la fecha no se han realizado trabajos de excavación arqueológicos sistemáticos en las PCR del Rímac, existen a nuestro juicio razones para suponer en este primer nivel de análisis que estas estructuras fueron contemporáneas con sus similares de Pachacamac. Sin embargo esta contemporaneidad tendrá que ser demostrada en un futuro próximo a fin de confirmar tanto el aspecto cronológico como el tipo de relación (ijerárquica?) que vinculaba las pirámides del Rímac con las de Pachacamac.

\section{PURUCHUCO: UN PALACIODEL HORIZONTETARDÍOENELRÍMAC}

Desde la perspectiva arquitectónica, y a pesar de las suspicacias que despertó su restauración entre la comunidad de arqueólogos de la época (9), Puruchuco muestra características sincréticas en su fábrica, pues su construcción es resultado evidente de la confluencia de dos tradiciones distintas: aquella propia de los grupos locales desarrollada durante el Intermedio Tardío, y otra de influencia Inca (ver Fig. 4; Cornejo, 2000; Villacorta, 2001). Podemos definir como atributos arquitectónicos de la tradición local algunos rasgos que Puruchuco comparte con las PCR, a saber: el muro perimétrico que aísla al edificio, la existencia de un solo acceso, un patio interior y una terraza o plataforma que, junto con la última, configuran la audiencia.

Sin embargo Puruchuco exhibe características distintas de las PCR. Podemos mencionar el desarrollo horizontal de los volúmenes arquitectónicos así como la evidente intención de restringir el ingreso y circulación de personas más allá de la audiencia. En su área reservada encontramos ambientes compatibles con la actividad residencial; en otro sector aparecen asociados un patio con depósitos interiores. En el último caso es evidente que el patio corresponde a zonas de laboreo donde se procesaban los productos almacenados en los depósitos contiguos. Cabe indicar que durante la limpieza de este patio se encontró un batán (10), hallazgo que se vincula al maíz registrado en los depósitos adyacentes (ver Fig. 5).

La dinámica de circulación restringida se reafirma en la clara intención de controlar la movilidad de las personas que ingresan y transitan por el edificio, propósito manifestado en vanos pequeños (portadas) y especialmente en corredores angostos.

(9) Ver discusión sobre la restauración de Puruchuco en Villacorta, 2004. Asimismo ver distintas atribuciones cronológicas de Puruchuco en Milla, 1974; Agurto, 1984; UNI-FORD, 1994.

(10) Comunicación personal de Arturo Jiménez Borja. En la actualidad este ambiente del Palacio aún exhibe el batán registrado durante los trabajos de limpieza. 


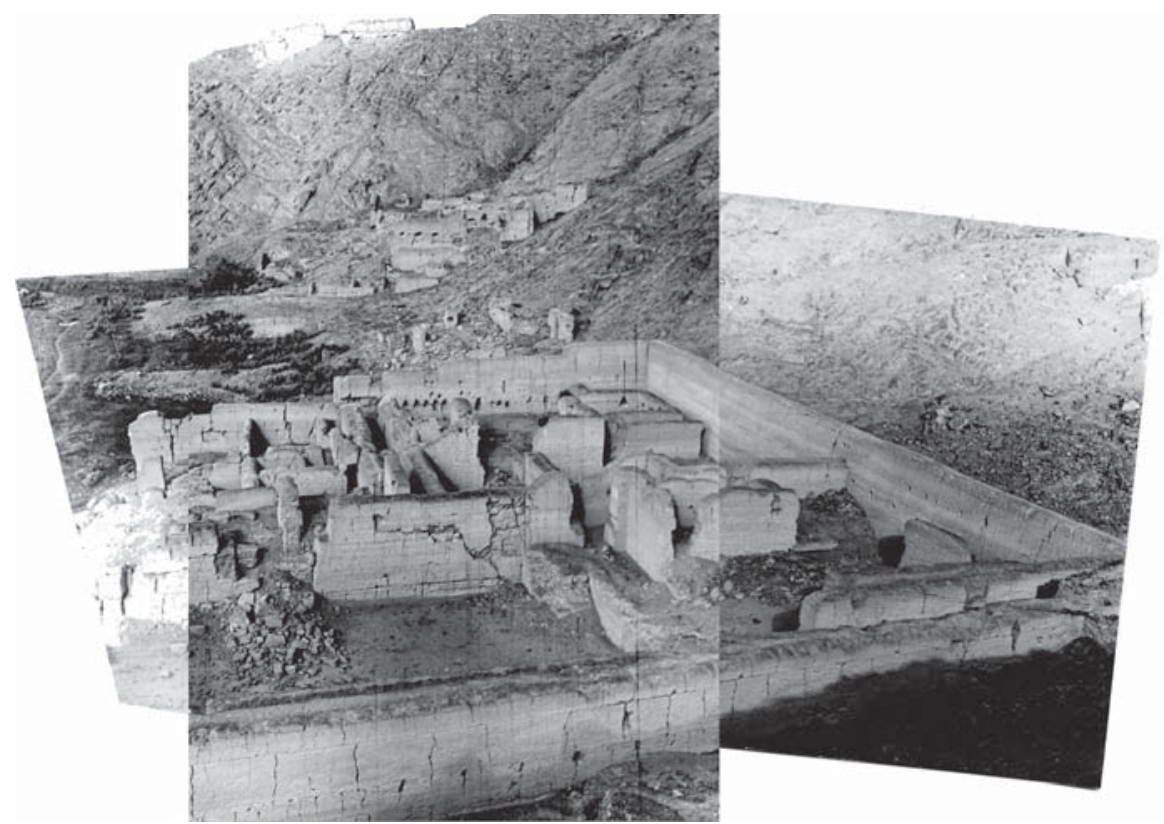

Fig. 4 - Puruchuco antes de su restauración. Foto Henri Reichlen, 1950. Archivo Sucesión Jiménez Borja.

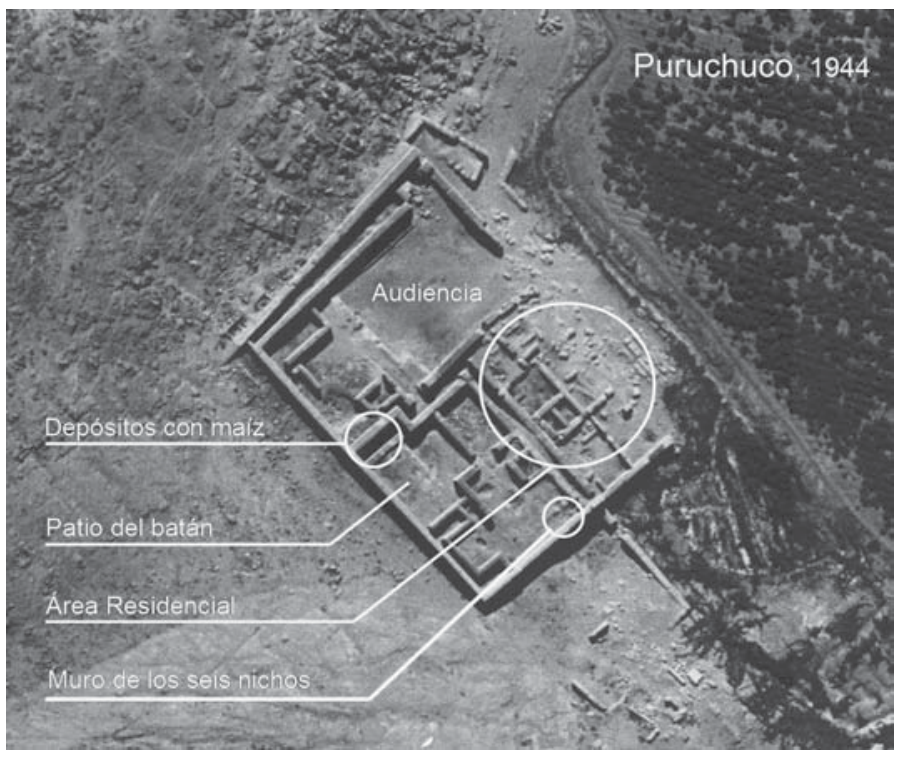

Fig. 5 - Puruchuco antes de su restauración (1944). Aparecen señalados las áreas relevantes para este estudio. Foto Servicio Aerofotográfico Nacional. 
Asimismo, el diseño de ciertos ambientes del edificio favorece al control del ingreso y circulación de las personas por sus patios y pasadizos. Estos atributos difícilmente pueden ser considerados casuales, considerando — además - que Puruchuco, como todo conjunto arquitectónico de ese tiempo, muestra señales inequívocas de haber sido el resultado del diseño y ejecución de un solo proyecto constructivo. Esto se deduce a partir de su tamaño "reducido", su edificación en un espacio previamente definido por un muro perimétrico, así como por la continuidad de su trazo y la preponderancia de una sola técnica constructiva: la tapia (verFig. 6). Así — a diferencia de las PCR—es posible afirmar que en Puruchuco las áreas compatibles con actividades residenciales o de vivienda formaron parte original del diseño monumental del edificio (Gasparini \& Margolies, 1977: 186; Jiménez Borja, 1988: 9, 13). Esta apreciación es particularmente importante, pues, luego del Horizonte Medio ocurrió un cambio de paradigma en la escala (¿y función?) de los edificios monumentales de la costa central: nunca más se levantaron construcciones de gran tamaño como aquellas de los periodos previos $(v . g$., Camajarquilla, Maranga, Huaca Juliana, Huaca Trujillo o Catalina Huanca para el periodo Intermedio Temprano y el Horizonte Medio; Villacorta, 2001; 2004 [11]).

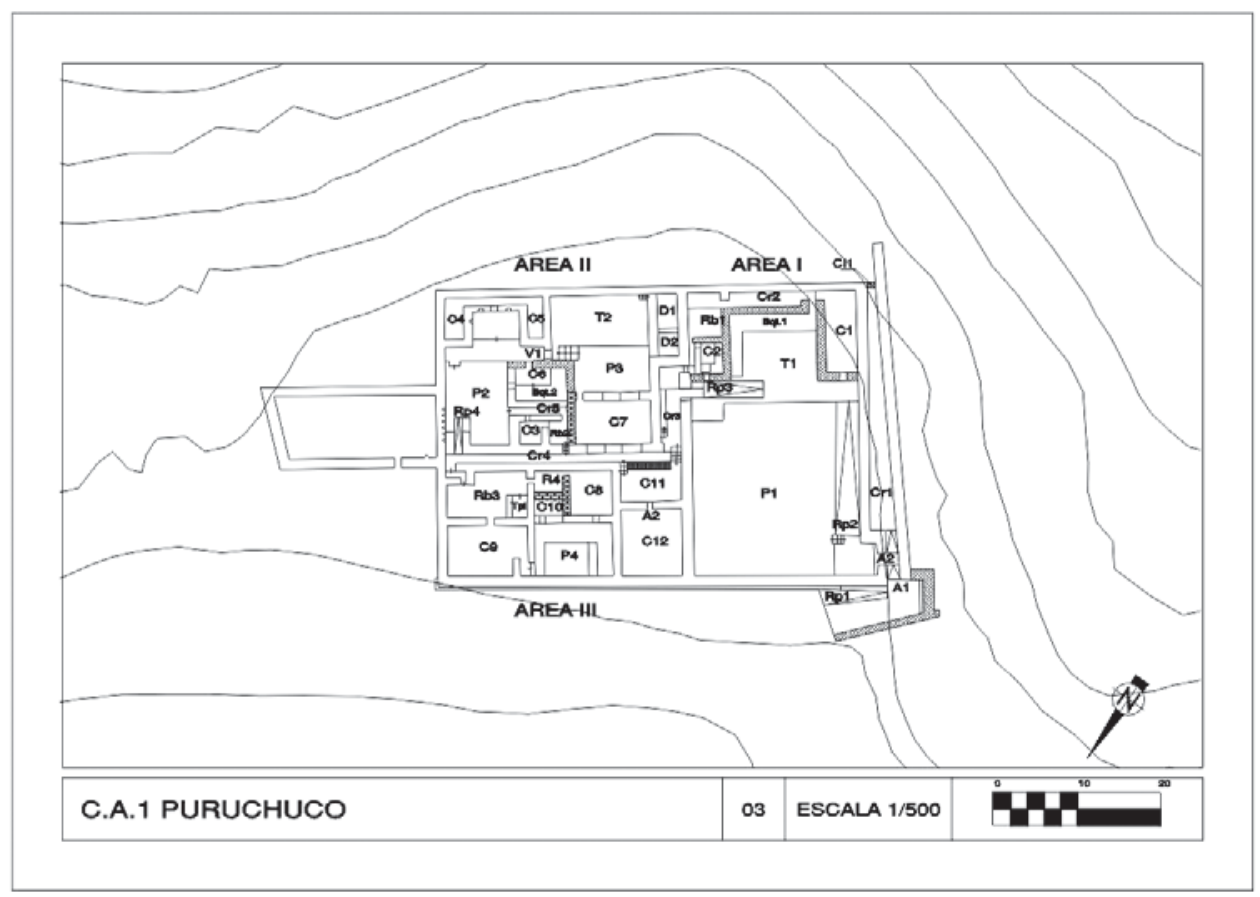

Fig. 6 - Puruchuco luego de su restauración.

(11) Si bien esta afirmación se puede generalizar, existieron algunas excepciones como algunas construcciones de Pachacamac o Mateo Salado. 
Por otra parte, la asimilación de componentes arquitectónicos de influencia Inca en Puruchuco es evidente; destaca el rectángulo o la típica "cancha" donde está "inscrita" la estructura ( $c f$. Cornejo, 2000; Villacorta, 2001 —ver Fig. 5-). A ello se suman los atributos ornamentales del estilo imperial cuzqueño, como vanos de forma trapezoidal, nichos triangulares y portadas de doble jamba (ver Figs. 7 y 8). Estos rasgos son compartidos, en mayor o menor medida, por otros importantes asentamientos Incas de la costa centro-sur, como Pachacamac (Shimada, 1991[1903], Uquira (Coello, 1998), Incahuasi (Hyslop, 1985: fotos 52, 68), o Tambo Colorado (Gasparini \& Margolies, 1977: fig. 184).

Ello no debe sorprender por que se sabe, gracias a las fuentes históricas, que los palacios o residencias de los incas fueron una variedad de construcción común en la arquitectura del Cuzco imperial, de la que incluso existieron diversos tipos (p.e. palacios en la ciudad del Cuzco, palacios de campo o de retiro así como palacios de funcionarios imperiales — adscritos a cuaracas, administradores provinciales, etc.- -). Al igual que sus símiles costeños, los palacios cuzqueños estaban reservados solo para la máxima autoridad (el Inca), su panaca, aliados de elites provinciales y los más altos funcionarios de la burocracia imperial (ver Kendall, 1985:56-67). Desde estos edificios se centralizaba buena parte de la toma de decisiones ordinarias concernientes a la administración del imperio y sus provincias.

Por otro lado, los objetos hallados en Puruchuco convalidan la afirmación de que el edificio corresponde a una construcción del Horizonte Tardío (Villacorta, 2001; 2004). Las evidencias son abundantes y representativas. Entre ellas destaca el hallazgo de dos keros de cerámica que en sus características dejan apreciar la mezcla de

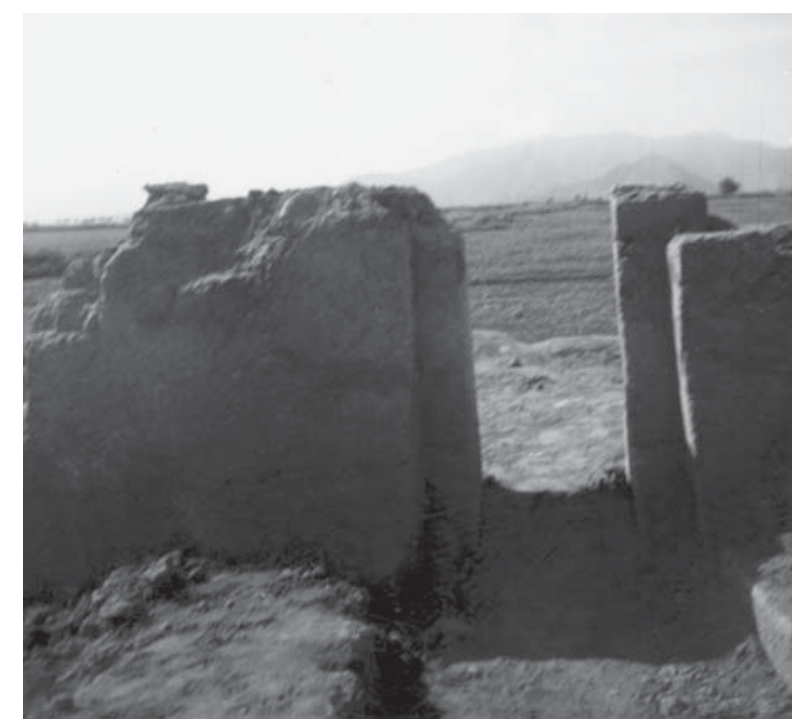

Fig. 7 - Portada de doble jamba de Puruchuco antes de su restauración. Archivo Museo de sitio Arturo Jiménez Borja-Puruchuco. Instituto Nacional de Cultura. 


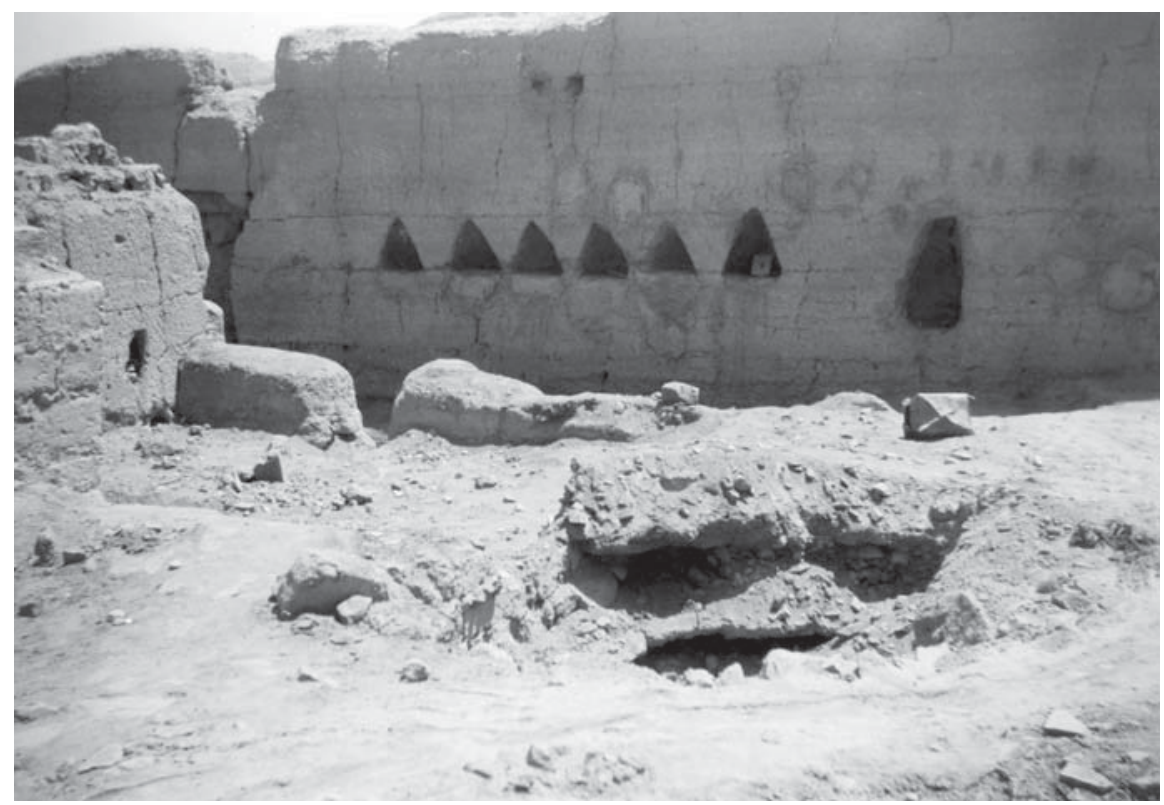

Fig. 8 - Vista del muro de los nichos triangulares apenas iniciada su restauración (circa 1953). Archivo Sucesión Jiménez Borja.

elementos incas (p.e. forma) con otros de tradición local (p.e. representaciones iconográficas; ver Figs. 9 y 10). Otro hecho que convalida el carácter inca del sitio es el hallazgo de más de veinte quipus en 1956. Este descubrimiento ocurrió al exponer un mausoleo intacto del Horizonte Tardío que contenía tres fardos funerarios (uno con falsa cabeza) enterrados en dos momentos distintos (Fig. 11). Todos los quipus fueron encontrados dentro de una olla cuya abertura estaba cubierta con un mate (Villacorta, 2004; Urton \& Brezine, Ms.).

Estudios recientes realizados en esta colección, en realidad "archivo de quipus", han demostrado que un grupo significativo de ellos contenía información numérica recurrente y estructurada en tres niveles jerárquicos (Urton \& Brezine, Ms). Incluso los autores postulan que algunos kipus tienen un "segmento introductorio" que muy bien podría identificar el topónimo del lugar de origen/destino de la información contenida en el quipu, es decir "Puruchuco" (Urton \& Brezine, Ms). Los estudios del "archivo de quipus de Puruchuco" aún se encuentran en proceso, sin embargo lo avanzado hasta la fecha es realmente alentador y brinda luces sobre el rol e importancia de este lugar en el esquema de orden político Inca de esta parte de la cuenca del río Rímac.

Siguiendo en este mismo tema, la función administrativa de Puruchuco se apoya también en el hallazgo de un número significativo, aunque indeterminado, de fieles de balanza. Estos instrumentos dan cuenta de actividades altamente especializadas y exclusivas, pues habrían sido utilizados para el control del peso de objetos de alta estimación en el mundo prehispánico como las hojas de coca. Por otra parte no puede 


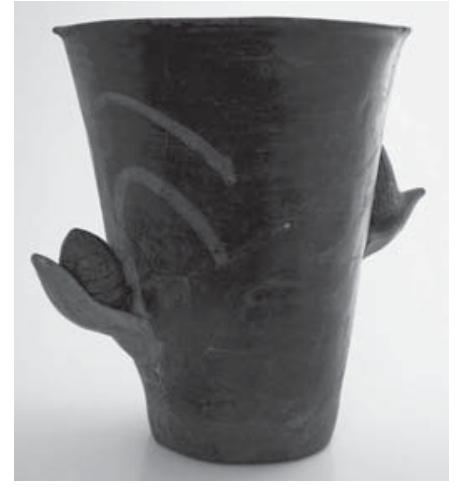

Fig. 9 - Kero de cerámica de Puruchuco. Museo de sitio Arturo Jiménez Borja-Puruchuco. Instituto Nacional de Cultura.

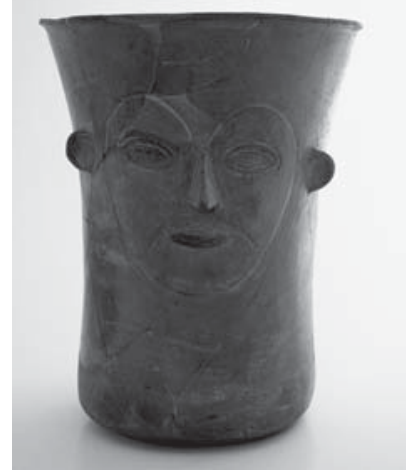

Fig. 10 - Kero de cerámica de Puruchuco. Museo de sitio Arturo Jiménez Borja-Puruchuco. Instituto Nacional de Cultura.

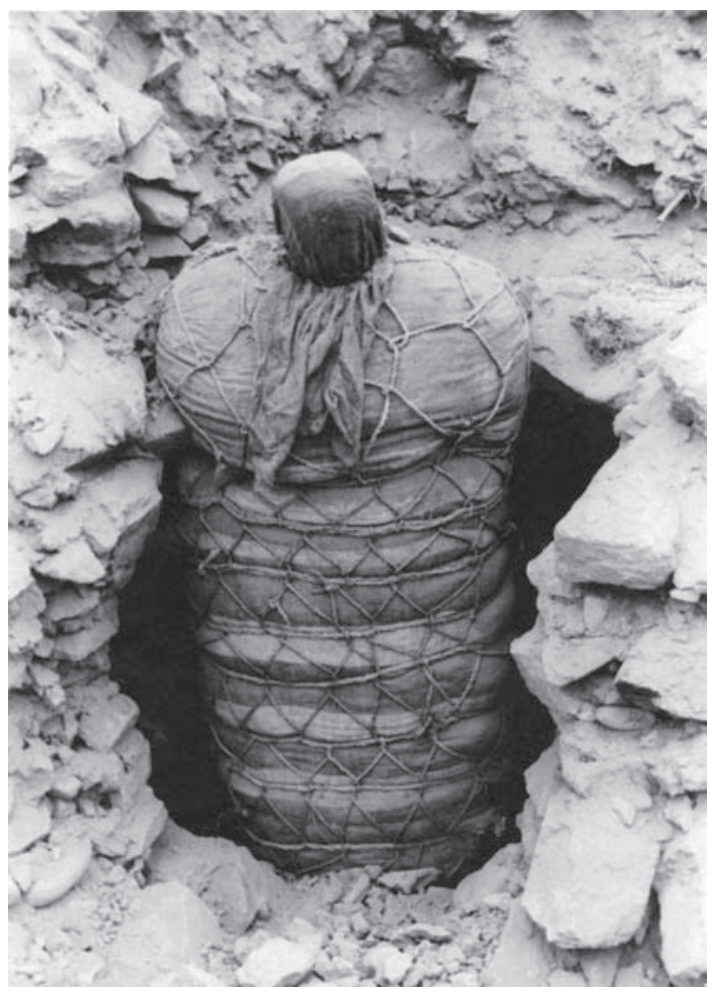

Fig. 11 - Fardo de falsa cabeza de Puruchuco (1956). Archivo Museo de sitio Arturo Jiménez Borja-Puruchuco. Instituto Nacional de Cultura. 
excluirse la posibilidad de que la audiencia haya sido el espacio de celebraciones de índole religiosa o propiciatoria animadas por música y danzas; prueba de ello fue el hallazgo de instrumentos musicales como tambores, antaras y quenas (Villacorta, 2004).

También es interesante constatar que en Puruchuco se realizaron detalladas observaciones astronómicas. Esta fue seguramente la función principal del recinto de los "seis nichos"; el juego de sombras proyectadas en las hornacinas y sus variaciones a lo largo del año permitieron controlar el ciclo anual del sol mediante el seguimiento de su movimiento en el horizonte (Wakeham Dasso, 1978 - ver Fig. 5 y 8-). La pericia para controlar esta información, así como su acceso, debió haber sido extremadamente reservada dada la ubicación de este ambiente en la zona privada del edificio.

Es así que desde la perspectiva definida en este artículo (v.g. su monumentalidad con respecto a los paradigmas de su época, las características y complejidad formal de su arquitectura, los materiales recuperados de cada uno de los ambientes de esta estructura y por la función de muchos de estos objetos asociados), Puruchuco puede ser definido como una residencia de elite o palacio, sede de la máxima autoridad local y probablemente vinculada directamente al Inca. Las funciones del edificio no se restringieron al ámbito doméstico o residencial, sino que fueron más amplias, cumpliéndose también importantes tareas de índole económica, administrativa e incluso religiosa, cuya influencia involucraba a la comunidad adscrita al jefe étnico o curaca (Villacorta, 2001; 2004).

\section{LA OCUPACIÓN INCA DEL VALLE MEDIO BAJO DEL RÍMAC}

La presencia Inca en el área de estudio se manifiesta en dos tipos de evidencia: la primera es la incorporación de criterios de edificación y ornamentación en la construcción de palacios cuyo ejemplo más característico es Puruchuco. La segunda corresponde a expresiones arquitectónicas que se basan en el trazo, a escala reducida, de criterios de emplazamiento y organización espacial semejantes a los denominados centros administrativos incas, los que consideran una serie de edificios tipo, como ushnus, kallancas, depósitos, etc. distribuidos en torno a una plaza (p.e. Gasparini \& Margolies, 1977; Hyslop, 1990).

Emplazamientos del último tipo han sido identificados en la Puruchuca, San Juan (Fig. 12) y con reservas en Huaycán de Pariachi. Todos exhiben rasgos particulares; lo que les otorga una apariencia poco usual en comparación a edificios semejantes de regiones costeras vecinas (Villacorta, 2001).

El único ushnu excavado es el de la Puruchuca, en cuya plataforma se encontró un ambiente elaborado de adobes cuyas paredes estaban finamente enlucidas de blanco; aquí se develó una columna redonda sobre la que aún se apoyaba un bowl de forma semicircular con un orificio precocción en su fondo (12) (ver Figs. 13 y 14). Según Zuidema, uno de los objetivos específicos de los ushnus sería correlacionar e integrar

(12) Agradecemos al Lic. Daniel Guerrero por compartir esta información además de las fotografías de este hallazgo a fin de ilustrar este artículo. 


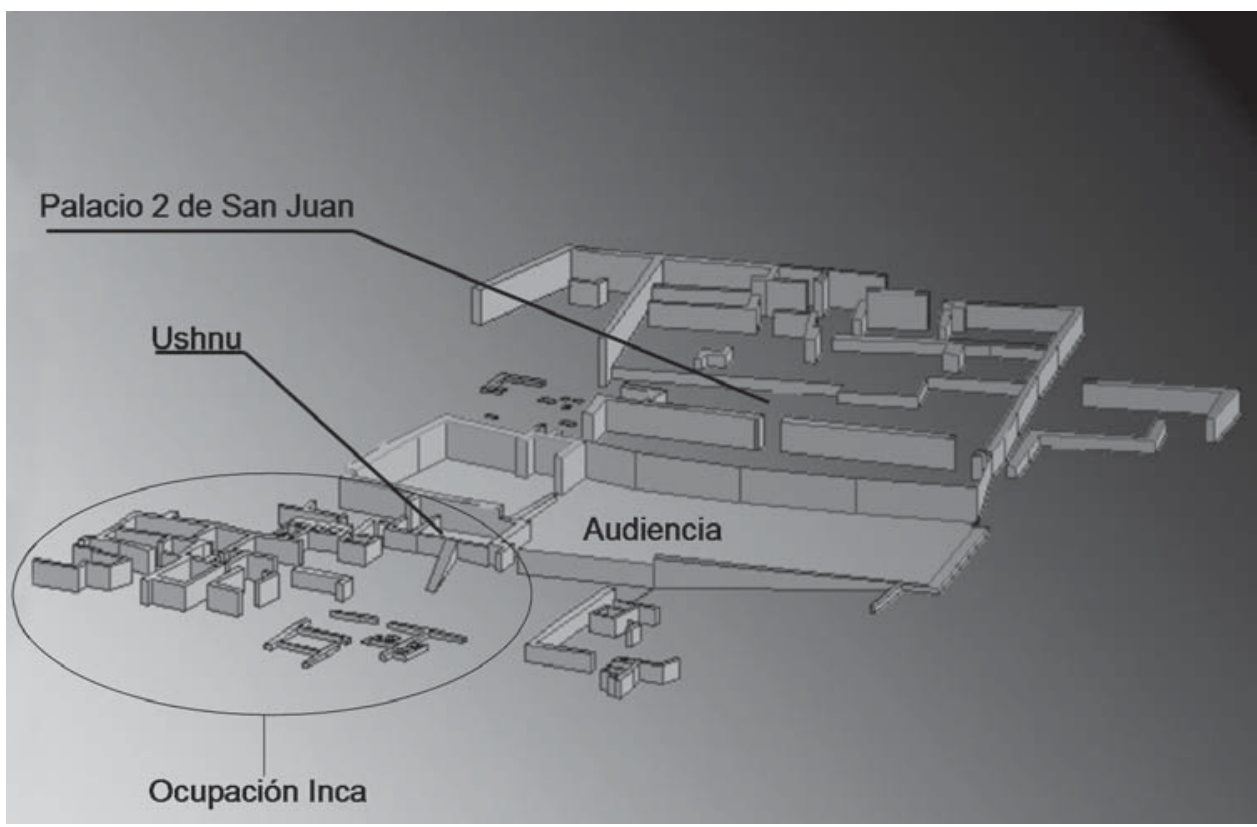

Fig. 12 - Detalle del Palacio ${ }^{\circ} 2$ de San Juan de Pariachi y las edificaciones de estilo Inca adyacentes donde destacan la plaza y el ushnu.

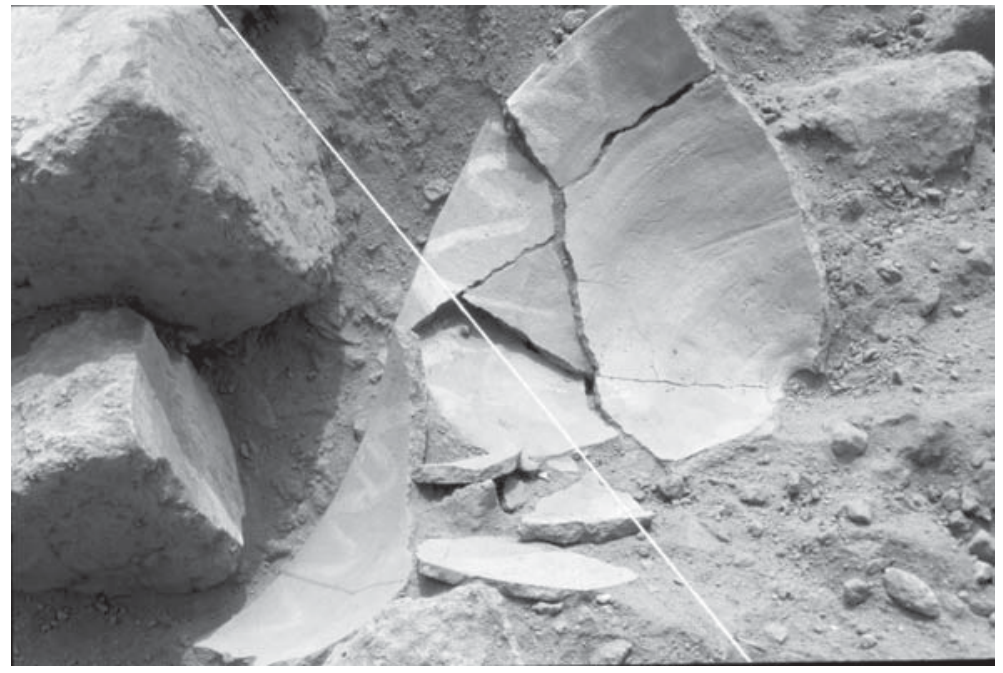

Fig. 13 - Vista del bowl donde se aprecia orificio precocción. Fue registrado sobre la columna de abobes que aparece en la Fig. 14. Cortesía Daniel Guerrero. 


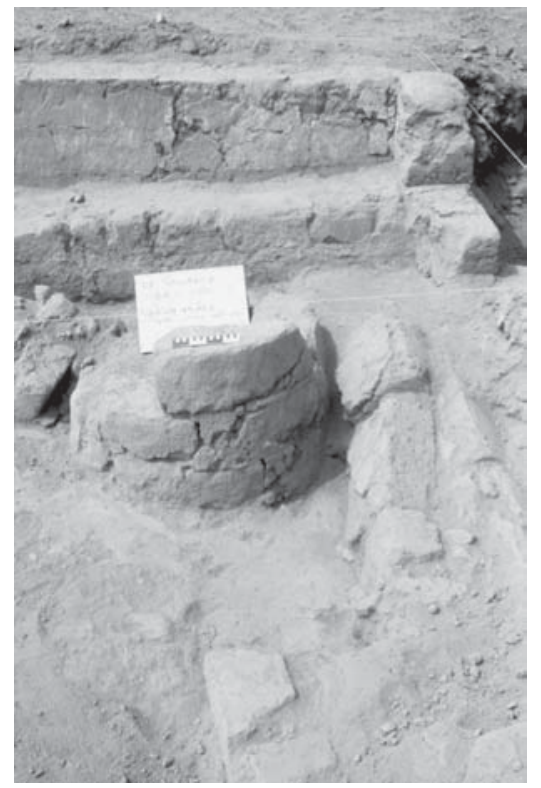

Fig. 14 - Vista de banqueta y columna de abobes enlucidos en blanco luego de la limpieza. Cortesía Daniel Guerrero.

los calendarios agropecuarios locales (p.e. de los grupos conquistados) a las necesidades de la organización económica, religiosa y política del imperio (1989). Mediante las actividades celebradas en los ushnus se formalizaban las relaciones simbólicas con los territorios conquistados, los que tienen claras connotaciones político-administrativas imbuidas de un fuerte espíritu religioso. De esta manera se establecieron obligaciones calendarias con respecto a la siembra y cosechas de los campos de cultivo en el ámbito local y cuya producción se dedicaba al imperio del Cuzco. En ese sentido la orientación de La Puruchuca y San Juan de Pariachi, alineadas con respecto a los ejes cardinales, es una evidencia de las consideraciones astronómicas tenidas en cuenta al momento de su construcción (Villacorta, 2001).

De acuerdo con las descripciones de los cronistas, el ushnu comprendía además de un escenario elevado para las celebraciones públicas, que podía ser una estructura artificial (pirámide) o un promontorio natural, una serie de objetos relacionados con la parafernalia oficial del Tahuantinsuyo, a saber: una silla o banqueta, una columna o mojón (13) y un recipiente para las libaciones, ya sea de chicha, sangre, cenizas o la mezcla de todos ellos. Hay que decir que el contexto en el que se registró el bowl hallado en la Puruchuca concuerda bien con esta definición, lo que favorece nuestra interpretación.

(13) Zuidema utiliza este término para hacer referencia a una columna o palo que no daba sombra cuando el sol, en determinadas épocas del año, se encontraba en su cenit (1989: 408 - 412). 
Al margen de detalles relacionados con el canon arquitectónico imperial, preferimos enfocar la discusión en las implicancias de la dominación Inca de la región. En ese sentido, debemos decir que la evidencia de Puruchuco es categórica en señalar que el palacio continuó representando el paradigma arquitectónico de la región durante el Horizonte Tardío. Esta visión puede darnos la impresión de una situación estática. Nada más lejos de la realidad (Guerrero, 2004; Cock \& Goicochea, 2004). Múltiples son las evidencias en todos los sitios de la región que dan cuenta de cambios significativos en este tiempo: la cultura material se transforma visiblemente; así la conspicua alfarería local tiende a homogeneizarse estilísticamente, especialmente en lo que respecta a los alfares utilitarios, probablemente los más relevantes desde el punto de vista económico (Guerrero, 2004). Asimismo a partir de la llegada de los incas a la costa central, se dinamiza el intercambio de piezas de estilo imperial de distintas provincias vecinas, cosa que no se observa con la misma intensidad para el periodo previo (Guerrero, 2004). De la misma manera todo parece indicar que las manufacturas textiles elevan su productividad como calidad (Rossana Mendoza, 2004). Maranga reverdece su antiguo esplendor y se desarrolla el impresionante sitio de Armatambo (Daniel Guerrero, 2004), cuyo apogeo es acompañado por un santuario de Pachacamac sometido a intensas remodelaciones (Hyslop, 1990).

La evidencia de numerosos (y quizás nuevos) contingentes humanos en la región se confirma con la aparición de cementerios en quebradas antes escasamente ocupadas (p.e. Huaquerones y La Rinconada). Se puede afirmar, a partir de la recurrencia vista en los ajuares funerarios registrados, que existió una especialización en las actividades económicas en cada una de las poblaciones representadas en estos cementerios, dedicadas tanto a la elaboración de textiles como a la orfebrería respectivamente (Cock \& Goicochea, 2004; Guerrero, 2004).

Por otra parte, en el estado en el que se encuentran nuestras investigaciones, resulta imposible postular siquiera una identidad histórica a la evidencias culturales registradas (¿nos encontramos ante el curacazgo de Lati?). Sin embargo la multitud de estructuras palaciegas y asentamientos complejos en el ámbito asociado a este canal nos hablan de una compleja estructura social, la que hace insoslayable el auxilio de fuentes históricas que contribuyan a enriquecer nuestros modelos explicativos fundamentados en el registro arqueológico.

Todo indica que en la región de estudio (valle medio bajo del Rímac) los incas respetaron el antiguo sistema previo a su llegada, en virtud de la eficiencia con el que funcionaba, y cuyos "cambios" probablemente se limitaron a elevar la productividad mostrada, pero sobre la base del tradicional sistema de organización costeño. Este sistema tuvo como símbolo en su nivel elemental, en lo material al palacio, y en lo social la relación del curaca con su grupo étnico y la administración concertada de la fuerza del trabajo. Muchos de los emplazamientos de estilo Inca registrados en el área de estudio representarían, más que una imposición coercitiva de los incas, una manifestación de las habilidades diplomáticas de los curacas locales a fin de conservar sus privilegios tradicionales ante las nuevas condiciones políticas impuestas por el Tahuantinsuyo. 


\section{LOS PALACIOS DURANTE EL INTERMEDIO TARDÍO: PARADIGMA DEL ORDEN POLÍTICO, SOCIAL Y ECONÓMICO DE LA COSTA CENTRAL}

Cabe preguntarse si complejos palaciegos similares a Puruchuco fueron construidos en el valle del Rímac antes de la llegada de los incas. Existe en efecto un grupo de edificios cuyo diseño integra una zona pública y otra privada. En ellos es posible identificar todos los rasgos correspondientes a la tradición local y que luego manifiestan su vigencia en la arquitectura de Puruchuco, como por ejemplo el muro perimétrico, el acceso restringido, la audiencia, patios interiores privados, finos depósitos cuadrangulares internos (con ménsulas para soportar techos de lajas), además de cuartos y recibos apartados, de buen acabado y perfectamente compatibles con la actividad residencial (ver Fig. 15 del palacio de Gloria Chica; Villacorta, 2001). Hay varias razones para pensar que estas estructuras fueron construidas durante el periodo Intermedio Tardío y que constituyen la manifestación de la tradición constructiva local.

El caso más evidente es aquel que ocurrió en el complejo arqueológico de San Juan de Pariachi, donde al denominado palacio 2, se adosa un emplazamiento que incorpora y desarrolla en su trazo una planta de clara influencia inca (ver Fig. 12). Este ejemplo de estratigrafía horizontal es una de las claves para atribuir una asignación cronológica relativa pero consistente a los palacios, esto es como edificios cuya tradición se remonta al Intermedio Tardío.

Por otra parte un atributo recurrente refuerza nuestra interpretación de esta categoría de edificio como palacio. Nos referimos al sistema de terrazas ubicadas sobre las laderas del cerro que definen el ámbito del sitio y que se asocia consistentemente a un anillo de silos o depósitos en sus inmediaciones. Es interesante notar que las terrazas, llamadas coloquialmente secaderos o tendales también han sido registradas en complejos PCR como Huaquerones y Monterrey en el Rímac (Villacorta, 2001) o Pampa de Flores y Huaycán de Cieneguilla en Lurín (Eeckhout, 1999).

Nos parece evidente que existen relaciones funcionales directas entre las terrazas y los silos identificados en su perímetro inmediato. Su asociación a abundantes cantidades de herramientas en la superficie, como manos de moler y batanes, nos hacen afirmar que ambos formaban parte de un mismo sistema de procedimientos (p.e. secado, molido, almacenado, etc.) a los que se sometían los diversos productos agropecuarios de la zona. Aquí se procesaban aquellos bienes que, a manera de tributo, eran ofrendados al curaca que habitaba el palacio, lo que hacían posible mantener vigentes los mecanismos de la reciprocidad. En síntesis los palacios eran centros de acopio, transformación y distribución de los recursos más importantes de la comunidad y referente fundamental de su idiosincrasia social. Las ofrendas eran insumos que se convertían en bienes suntuarios como tejidos, cerámica o metales o bien en comidas y bebidas, los que eran a su vez redistribuidos y consumidos entre los diferentes estamentos de la sociedad prehispánica de la costa central como de otras partes del litoral, especialmente la costa norte (ver Ramirez Horton, 2001). A pesar de que el trazo y fábrica de los palacios son diferentes, ya que no existe una estandarización tanto en su diseño 


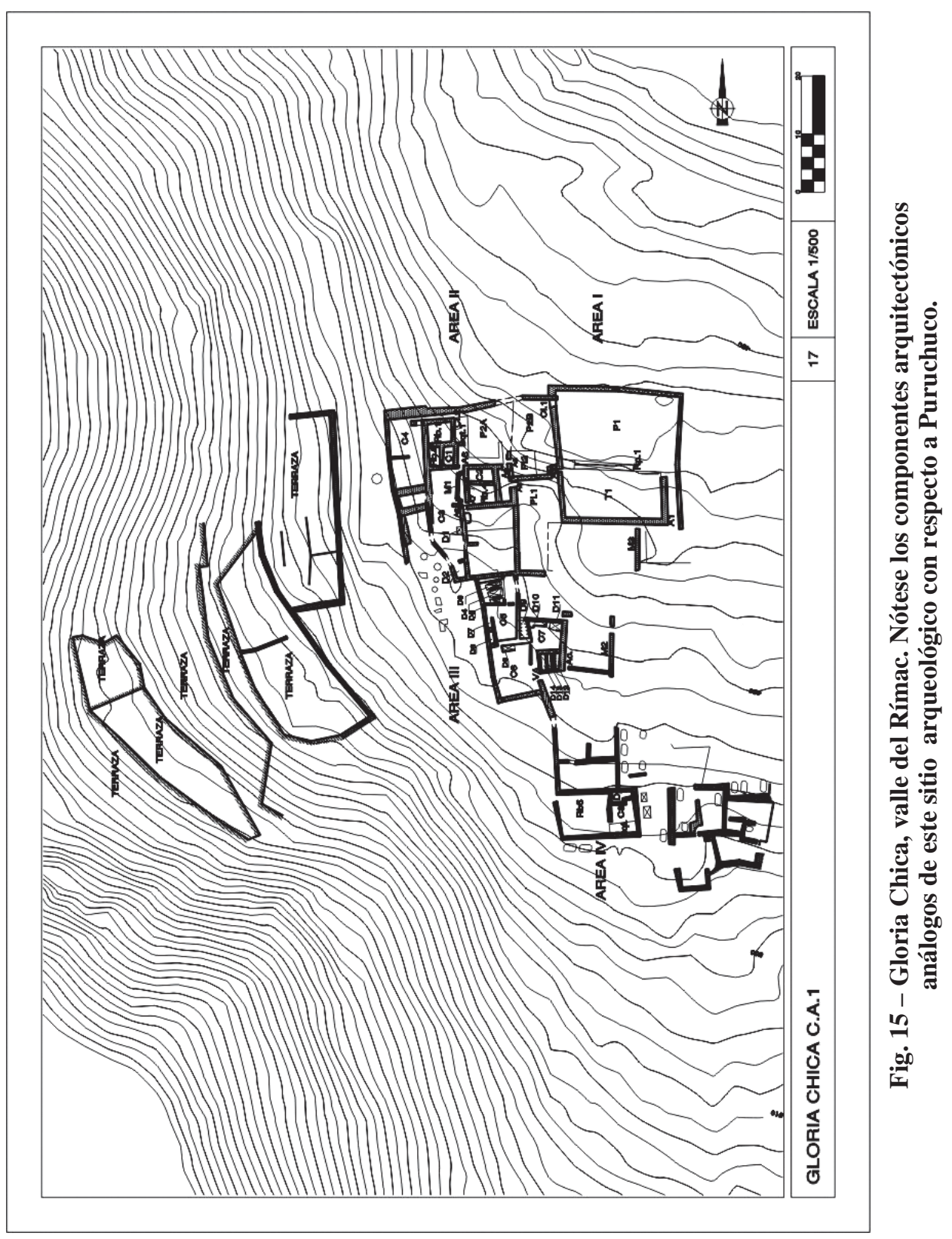


como en elementos y técnicas constructivas, ellos comparten los mismos componentes arquitectónicos, lo que expresa una racionalidad común y no es más que la manifestación de una misma función. En ese sentido Puruchuco simboliza la continuidad y expresión material de esta concepción, pero en un momento distinto: el Horizonte Tardío.

\section{ARQUITECTURA, FUNCIÓN Y PODER DURANTE EL INTERMEDIO TARDÍO}

De lo expuesto proponemos que fue el palacio el edificio que dio coherencia a los patrones arquitectónicos y de asentamiento del valle medio bajo del Rímac durante el Intermedio Tardío. Desde aquí los curacas yungas regían los destinos de las poblaciones adscritas a su régimen y se establecían los vínculos que configuraban el tramado político y económico de la región.

Por lo general estos conjuntos residenciales están rodeados por una serie de construcciones menores, de las que existen tres tipos, a saber: ambientes de configuración ortogonal elaborados de barro y piedra (recintos rústicos). Estos suelen formar una serie de construcciones de apariencia desordenada, casi siempre ubicadas en el espacio que queda entre el palacio y los campos de cultivo. Lamentablemente solo tenemos referencia de un proyecto arqueológico que realizó excavaciones en una edificación de estas características: Monterrey I (ver Tosso, 1997). Los trabajos en este lugar pusieron en evidencia cuartos ortogonales, que presentaban en todas sus esquinas pequeños recintos elaborados para contener grandes vasijas de almacenamiento de líquidos (p.e. agua o chicha). Sobre los pisos se encontró abundante material para la manufactura artesanal (p.e. piedras para moler, pulidores, piruros para tejer, etc.). Estos artefactos dan cuenta fidedigna del tipo de actividades que se realizaban en estos ambientes (Villacorta, 2001: mapa 8). De alguna manera esta variedad de estructuras, por sus características y materiales asociados, cumplían funciones de servicio de atención a la estructura principal o palacio al que estaban asociados. Ellos nos recuerdan en mucho a los SIAR (14) de Chan Chan, los que ciertamente cumplían una función análoga a la descripción antes señalada (Topic, 1980).

El segundo tipo de estructuras asociadas son los tendales o secaderos, los que se apoyan en flanco empinado de los cerros. Por último existen los silos o depósitos soterrados de forma circular, cuyas paredes están revestidas de piedra y que en la mayoría de casos están asociados a gran cantidad de manos de moler y batanes (ver Figs. 15 y 16 en este artículo).

Las edificaciones de la periferia (recintos rústicos, tendales y silos) son elementos recurrentes y resultado de las necesidades derivadas de los requerimientos propios del palacio, formando una misma unidad, es decir que son partes de un todo que le otorga una función, personalidad y coherencia a la arquitectura de la época (ver Fig. 16). Estos complejos son el referente directo del orden y organización social de la región durante el Intermedio Tardío. Sus pretenciones públicas son distinguibles también si apreciamos

(14) Small Irregular Aglutinated Rooms por sus siglas en inglés. 


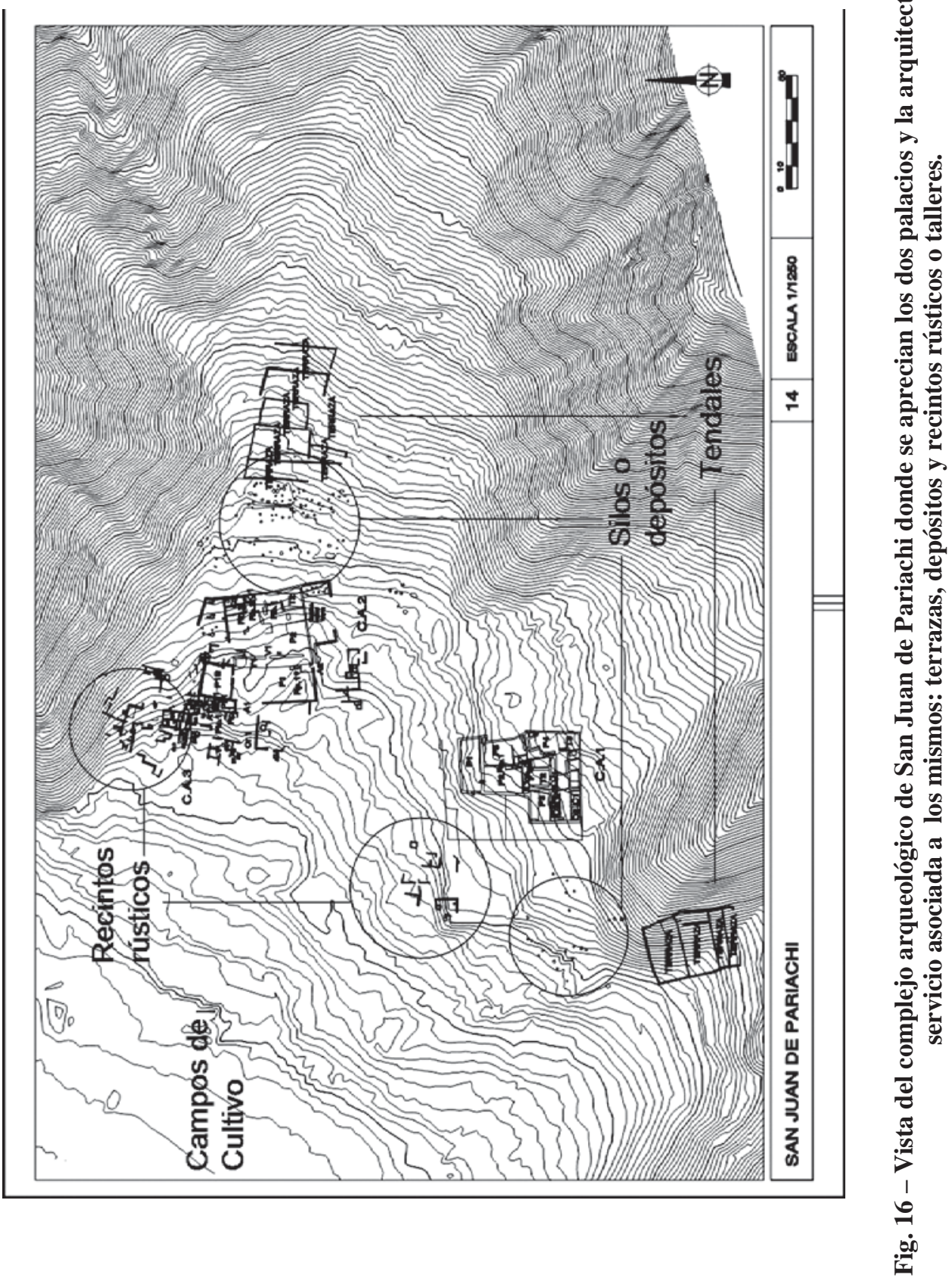


el lugar que ocupan, siempre sobre los flancos áridos, al pie de las áreas cultivables, pero donde el edificio resaltaba nítidamente con respecto al paisaje circundante, adquiriendo así una prominencia que le otorga un carácter omnipresente.

Palacios e infraestructura complementaria (v.g. recintos rústicos, tendales y silos) permitieron atender dos niveles fundamentales de la organización del poder en la Costa Central de la época: el primero era aquel constituido por el curaca, que veía recompensada su habilidad para gobernar recibiendo constantemente tributo de sus fieles, reafirmado así los privilegios ancestrales que justificaban su status social. Los comunes debían obediencia a su autoridad directa, sea brindando su fuerza de trabajo, sea sus productos agropecuarios. A cambio veían retribuidos sus esfuerzos y obediencia en la garantía de un excedente lo suficientemente amplio a fin de que beneficie a la población en general, manteniendo así la salud social, una de cuyas manifestaciones más significativas eran las festividades o banquetes durante los cuales la población gozaba de la "hospitalidad" del Señor. Se trata de una relación simbiótica, donde ambas partes se necesitan mutuamente y el balance en sus relaciones se obtiene mediante mecanismos simbólicos de reciprocidad y redistribución, ya que en la práctica es probable intuir una distribución asimétrica de los recursos sociales y económicos en favor del curaca. Los recursos y despliegue suntuario de la parafernalia que adornaba a los curacas (p.e. tejidos, arte plumario, metalurgia, etc.) es una manifestación inequívoca de esta tendencia (ver al respecto Mendoza, 2004; Vetter, 2004).

El segundo nivel es aquel que exigía al curaca establecer relaciones con sus pares (otros curacas), como con autoridades jerárquicamente superiores (p.e. deidades del ámbito regional como Pachacamac). Este tipo de relaciones privilegiadas se articulaban mediante mecanismos sociales análogos a los señalados en el párrafo anterior. Sin embargo tienen manifestaciones distintas, uno de cuyos rasgos particulares es la circulación de una variedad de presentes u obsequios privativos de los grupos de status superior, casi siempre manufacturas de alta calidad como tejidos, cerámica o metales. Así el palacio no solo es la vivienda de la autoridad más importante de la comunidad (el curaca), sino también es la sede donde se centraliza la toma de decisiones con respecto al futuro de la misma (15) (Villacorta 2001; 2004).

En ese sentido la comparación de los palacios con las PCR es insoslayable. Su relación con Pachamamac es evidente, siendo las del Rímac mucho más pequeñas. Ambas comparten sus rasgos formales distintivos como la misma lógica de crecimiento. ¿Podría tratarse de estructuras vinculadas a las autoridades que controlaban a las poblaciones que tributaban directamente al santuario de Pachacamac? Este es un postulado cercano al concepto de enclave territorial, que con algunos matices ha tenido algunos defensores (p.e. Jiménez Borja [1985] y su tesis de las "embajadas provinciales"; así como Rostworowski [1978] y "las tierras de la huaca"). La clave para dilucidar esta inquietud está en los elementos constitutivos que palacios y pirámides comparten, como la audiencia, depósitos y tendales. Porende, es válido sostener que las PCR y los palacios

(15) María Rostworowski (1978; 1981, 1989) y Susan Ramirez Horton (1996) analizan y brindan muchos ejemplos de esta modalidad de relación económica y social para los grupos costeños de la Costa Central y Costa Norte, respectivamente. 
cumplían funciones análogas en su faceta pública, es decir a través de ellas se procedía a la recolecta, transformación, almacenamiento y redistribución de una serie de productos, ya sean agropecuarios o manufacturados (Jiménez Borja, 1985; Franco, 1998).

En el caso de los palacios, el curaca y sus allegados fueron los administradores o destinatarios finales de los productos almacenados. Estos recursos, casi siempre manufacturas, fueron el valor circulante fundamental de las redes de reciprocidad e intercambio de más alto nivel en el mundo prehispánico andino en general (p.e. Rostworowski, 1978; 1981; Ramirez Horton, 1996). Por otra parte estamos tentados a postular la hipótesis que las PCR constituían espacios ritualizados cuyos elementos constitutivos evocan simbólicamente a un destinatario lejano: el oráculo de Lurín. Los curacas que ocupaban el lugar privilegiado en la cima de la plataforma de PCR serían los encargados de enviar los productos locales con destino a Pachamamac, dedicarlos a la celebración local de la misma deidad o garantizar la manutención de los contingentes humanos que cumplían faenas para el santuario en esta parte del Rímac. En los Andes prehispánicos, por razones ambientales y de tradición tecnológica, el control de la mano de obra resulta más importante y práctico que el control del territorio (Golte, 1987).

Sin embargo en el caso de la costa este escenario adquiere características particulares si consideramos, como lo sostiene María Rostworowski (1978), que una de las funciones de las acequias fue que su trazo a través de las áreas cultivables era utilizado como señal o límite de los territorios que conformaban cada uno de los curacazgos. Esta interesante afirmación nos introduce al tema de la territorialidad (entendida como el ejercicio de una autoridad sobre un espacio determinado) y definido a partir de señales físicas (p.e. acequias o canales). A partir de ello planteamos la hipótesis que los territorios del curacazgo (¿o del curaca?) no estuvieron señalados por el trazo físico del canal, sino por la extensión de los campos que ellos podían regar y cultivar gracias a la fuerza de trabajo de los contingentes humanos que dirigían.

Sin duda debió existir una jerarquía de canales y ramales, los que exigían diversa intensidad en su control y cuidado, lo que con seguridad tenía algún significado en el orden social, político y económico entre los curacazgos de los valles bajos del Rímac y Lurín (Villacorta, 2001). Es probable considerar que hechos como la variedad de cultivos, su destino final (p.e. curaca, festividades religiosas, autoconsumo, etc.), la época del año de la siembra y cosecha, así como la apertura o clausura de las bocatomas, influenciaban decididamente en el ámbito susceptible de irrigar, y por lo tanto en el control y administración del recurso hídrico como los resultados de la cosecha.

Es probable que el alcance de la autoridad, y por lo tanto de control sobre un territorio determinado, debió de haber estado regido por algunos de los criterios antes señalados. Así las fronteras o límites entre los curacazgos bien pudieron no ser tan rígidos, adaptándose al papel que le correspondía desempeñar a cada grupo de acuerdo al propósito del cultivo. La organización de estas actividades y la asignación de roles (p.e. limpieza del canal, preparación del terreno, siembra, control del riego, cosecha, barbecho, etc.), bien pudieron ser controlados utilizando dos sistemas no excluyentes: a partir de una autoridad centralizada o por mecanismos de reciprocidad básicamente simétricos. Si esta observación es valida, las PCR se entenderían como los espacios en 
los que se renovaban de manera periódica y cíclica los vínculos que relacionaban a los grupos del Rímac con aquellos de Pachacamac bajo cualquiera de las modalidades antes señaladas, y probablemente al amparo de lazos de parentesco entre los ancestros y autoridades locales y el ancestro divino universal: el oráculo de Lurín.

Es evidente que las necesidades sociales que dieron origen a las PCR fueron institucionalizadas y renovadas cíclicamente, como se comprueba en la construcción y superposición de varias de estas estructuras en un mismo complejo arqueológico (p.e. Pachacamac, Pampa de Flores, Tijerales, Panquilma, Huaquerones, Monterrey, Huanchihuaylas, etc. Ver p.e. Eeckhout, 1999; Villacorta, 2001).

\section{A MANERA DE CONCLUSIÓN}

De acuerdo con lo expuesto, se puede plantear que la residencia de elite (v.g., palacio) fue la edificación más importante en el área durante el Horizonte Tardío. Es decir, al igual que en el periodo Intermedio Tardío, el palacio fue la construcción que dio a la vez coherencia a los patrones de asentamiento y se constituyó en el fiel reflejo de la organización social de la costa central.

Todo hace indicar que, en la región estudiada, los incas respetaron el sistema previo, en virtud de su eficiencia económica. Los "cambios", probablemente, se limitaron a elevar la productividad mostrada, pero sobre la base del mismo sistema de organización (p.e. traslado de mitimaes a esta región). En este sentido, Puruchuco simboliza la continuidad de esta concepción, pero en un momento distinto: el Horizonte Tardío (Villacorta, 2001; 2004). No se puede descartar la posibilidad de que, durante el Horizonte Tardío, continuase la construcción de residencias de elite con los cánones arquitectónicos tradicionales ( $c f$. Villacorta, 2001: Anexo 1 de Puruchuco).

Por otra parte, en la zona investigada, las formas arquitectónicas de plazas y altares (ushnus), articulaban el calendario agrícola local, con el ciclo agrario oficial del Tahuantinsuyo. Estas estructuras representarían una rápida y eficiente capacidad de reacción de los curacas locales ante el nuevo orden político representado por el dominio del Tahuantinsuyo. La continuidad en la ocupación de los asentamientos del Periodo Intermedio Tardío es la primera evidencia de esta posibilidad. Esto queda reafirmado en la escala reducida de los edificios de "influencia inca" — a todas luces, secundarioscon respecto a los conjuntos arquitectónicos vecinos del mismo asentamiento, en su mayoría, residencias de elite o palacios de tradición local (v.g., CA 1 y 2 de San Juan de Pariachi; ver Fig. 16). Además, se debe tener en cuenta al poco cuidado en conservar rasgos "ortodoxos" de la arquitectura imperial Inca, tanto en técnicas constructivas, como en su trazo, considerado solo en sus formas más elementales. Asimismo debe mencionarse que los sectores atribuibles al desempeño de actividades específicas, como talleres y depósitos asociados a estos asentamientos (v.g., áreas de servicios), son bastante reducidos como para haber gozado del interés directo del Tahuantinsuyo. Hay que señalar que todos los rasgos mencionados se encuentran en los componentes arquitectónicos de gran escala, comunes en todos los asentamientos incas denominados "centros administrativos", que —incluso — tuvieron un ámbito de influencia regional durante su funcionamiento (v.g., Huanuco Pampa, Morris \& Thompson, 1985: Pumpu, 
Matos, 1994, y Jauja, D’Altroy, 1992). Si, además, se considera la gran riqueza de los territorios costeños, la eficiencia y productividad de la mano de obra yunga, y el uso que los curacas locales pudieron hacer de estos valores como herramienta de negociación política ante los incas (a fin de conservar sus privilegios tradicionales), entonces esta alternativa de interpretación parece la más veraz ante el estado actual de nuestros conocimientos.

La influencia de la ocupación Inca no sólo se aprecia en la arquitectura, sino en casi toda la cultura material de la región. En este sentido, destaca la gran influencia de los diseños de la cerámica, la textilería, así como los trabajos en madera y demás manufacturas. Todas estas evidencias tienen una peculiaridad muy interesante: muestran una gran libertad en la representación de los elementos o iconos de la tradición religiosa local sobre soportes de tradición cuzqueña. Si bien la ausencia de contextos bien documentados impide señalar claramente la procedencia de la mayoría de piezas (p.e. Hyslop \& Mujica, 1992), las recientes investigaciones demuestran que los objetos híbridos del contacto entre ambas tradiciones habrían estado al alcance de todos los niveles sociales de la época (Eeckhout, 1999: 361, fig. 10.23). En ese sentido es muy probable que los curacas locales en todos los niveles jerárquicos de la organización política tradicional (p.e. hatun curaca, curacas, mandones, mandoncillos, etc.) tuvieran un rol fundamental en la política de difusión y asimilación de los nuevos iconos y soportes propios de la religiosidad cuzqueña. La validación social de esta política se debió sustentar en un control efectivo de las redes de reciprocidad y redistribución social, las que tenían al palacio como catalizador de los acuerdos (entre curacas locales e incas —o sus representantes-), de los recursos naturales y sociales así como de las redes de distribución e intercambio de subsistencias y bienes suntuarios. Este esquema tan permisivo y a la vez políticamente efectivo, solo pudo ser posible en el marco de un tipo de dominación incruenta, que, probablemente, estaba sustentada en algún acuerdo o alianza de carácter pacífico.

\section{Referencias citadas}

AGURTO, S., 1984 - Lima Prehispánica, 177p.; Lima: FINAMPRO-Municipalidad de Lima. ANDERS, M., 1986 - Dual organization and calendars inferred from the planned site site of Anzangaro. Wari Administrative Strategies. Phd. Dissertation. Vol I, II y III. University Microfilmes International; Michigan: Ann Arbor.

ANDREWS, A., 1980 - Estructuras en U, símbolo del poder imperial. In: Chan Chan, Metrópoli Chimú: 167-180; Lima: Instituto de Estudios Peruanos-Instituto de Investigación Tecnológica Industrial y de Normas Técnicas.

BONAVIA, D., 1991 - Perú. Hombre e Historia. Tomo I: De los orígenes al S. XV, 586p.; Lima: Ediciones Edubanco.

BRACK EGG, A., 1996 - Introducción. In: Kuntursuyo. El Territorio del Cóndor: 19-43; Lima: Editorial Peisa.

CAVALLARO, R., 1997 - Architectural Análisis and Dual Organization in the Andes. In: Arqueológica Peruana 2. Arquitecturay civilización en los Andes Prehispánicos (Elisabeth Bonnier \& Henning Bishop, eds.): 42-61; Mannheim: Sociedad de Arqueológica Peruano Alemana Reiss Museum Mannheim. 
CERDAN, A. \& PONTERO, S., 1793 - Tratado sobre las aguas de los valles de Lima, presentado por el Señor Don Ambrosio Cerdan de Landa y Simón Pontero. In: Mercurio Peruano Tomo VII; Lima.

CIEZA DE LEÓN, P., 1986[1553] - Crónica del Perú, primera parte, 352p.; Lima: Pontificia Universidad Católica del Perú-Academia Nacional de la Historia. Introducción de F. Pease G.-Y. 2da. Ed. Colección Clásicos Peruanos.

COBO, B., 1964[1639]-Fundación de Lima. In: Obras del padre Bernabé Cobo de la Compañía de Jesús (edición y estudio preliminar de F. Mateos): 279-460; Madrid: Atlas. Biblioteca de Autores Españoles XCI-XCII. 2da. Ed.

COCK, G. \& GOYCOCHEA DÍAZ, C. E., 2004 - Puruchuco y el Cementerio Inca de la Quebrada de Huaquerones. In: Puruchuco y la sociedad de Lima: Un homenaje a Arturo Jiménez Borja (Luis Felipe Villacorta, Luisa Vetter \& Carlos Ausejo, eds.); Lima: CONCYTEC-Compañía de Minas Buenaventura y Diagnósticos Gammagráficos.

COELLO, A., 1998 - La ocupación inca en el valle de Asia, Perú. Tahuantinsuyu, An International Journal of Inca Studies, Vol. 5: 44-52; Canberra. Australian National University.

CORNEJO, M., 2000 - La nación Ychma y la provincia Inca de Pachacamac. Arqueológicas, $\mathbf{N}^{\circ}$ 24: 149-173; Lima: MNAAH-Instituto Nacional de Cultura.

D’ALTROY, T., 1992 - Provincial Power in the Inka Empire, 272p.; Washington: Smithsonian Institute.

EECKHOUT, P., 1999-Pachacamac durantl'Intermédiaire Récent. Étude d'un site monumental préhispanique de la Côte Centrale du Pérou, 504p.; Oxford: BAR International Series.

EECKHOUT, P., 2000 - Investigaciones arqueológicas en la pirámide $\mathrm{N}^{\circ}$ III de Pachacamac, costa central de Perú. Estudios Latinoamericanos, $\mathbf{n}^{\circ}$ 20: 19-40; Varsovia.

FRANCO JORDÁN, R., 1998 - La pirámide con rampa $N^{\circ} 2$ de Pachacamac. Excavaciones y nuevas interpretaciones, 105p.; Trujillo.

GASPARINI, G. \& MARGOLIES, L., 1977 - Arquitectura Inca, 347p.; Caracas: Centro de Investigaciones Históricas y Estéticas. Facultad de Arquitectura y Urbanismo. Universidad Central de Venezuela.

GOLTE, J., 1987 - La racionalidad de la organización andina; Lima: Instituto de Estudios Peruanos.

GUERRERO, D., 2004 - Cronología cerámica y patrones funerarios del valle del Rímac: una aproximación a los periodos tardíos. In: Puruchuco y la sociedad de Lima: Un homenaje a Arturo Jiménez Borja (Luis Felipe Villacorta, Luisa Vetter \& Carlos Ausejo, eds.); Lima: CONCYTEC-Compañía de Minas Buenaventura y Diagnósticos Gammagráficos.

HYSLOP, J., 1985 - Inkahuasi, the New Cuzco; BAR International Series 234.

HYSLOP, J., 1990 - Inca Settlement Planning, 377p.; Austin: University of Texas Press.

HYSLOP, J. \& MUJÍCA, E., 1992 - Investigaciones de A. Bandelier en Armatambo. Gaceta Arqueológica Andina, Vol. VI, n² 22: 63-86; Lima: INDEA.

INSTITUTO GEOGRÁFICO MILITAR (IGM), 1989 - Atlas del Perú, 397p.; Lima: Ministerio de Defensa.

JIMÉNEZ BORJA, A., 1985 - Pachacamac. Boletín de Lima, 7(38): 40-54; Lima: Editorial los Pinos.

JIMÉNEZ BORJA, A., 1988 - Puruchuco; Lima: Biblioteca Nacional del Perú. Serie PERULIBROS. Prólogo Juan Mejía Baca.

KENDALL, A., 1985 - Aspects of Inca Architecture: description, function and chronology, 2 vols.; Oxford: BAR international Series 242.

MACKEY, C., 1987 - Chimu Administrative in the Provinces. In: The Origins and Development of the Andean State (J. Hass, S. Pozorski \& T. Pozorski, eds.): 121-129; Cambridge: Cambrigde University Press. 
MATOS, R., 1994 - Pumpu, centro administrativo Inca de la Puna de Junín, 327p.; Lima: Editorial Horizonte, Fondo editorial del Banco Central de Reserva y Taraxacum editores.

MENDOZA NEYRA, R., 2004 - El tocado de Puruchuco. In: Puruchuco y la sociedad de Lima: Un homenaje a Arturo Jiménez Borja (Luis Felipe Villacorta, Luisa Vetter \& Carlos Ausejo eds.): 141-155; Lima: CONCYTEC-Compañía de Minas Buenaventura y Diagnósticos Gammagráficos.

MILLA, C., 1974 - Inventario, Catastro y Delimitación del Patrimonio Arqueológico del valle del Rímac y Santa Eulalia; Lima: Centro de Investigación y Restauración de Bienes Monumentales. Instituto Nacional de Cultura, INC.

MOORE, J.,1996 - Architecture and power in the ancient Andes. The archaeology of public Buildings, 255p.; Cambridge: Cambridge University Press. New Studies in Archaeology.

MORRIS, C. \& THOMPSON, D., 1985 - Huánuco Pampa. An Inca City and its Hinterland, 181p.; London: Thames and Hudson.

OFICINA NACIONAL DE EVALUACIÓN DE RECURSOS NATURALES (ONERN), 1975 - Inventario y evaluación de los recursos naturales de la zona del Proyecto Marcapomacocha, Vols. 1 y 2; Lima: Instituto Nacional de Planificación.

PAREDES BOTÓN, P. \& FRANCO, R., 1987 - Pachacamac: las Pirámides con Rampa, cronología y función. Gaceta Arqueológica Andina, 4(13): 5-7; Lima: INDEA.

PULGAR VIDAL, J., 1996 - Geografía del Perú, 302p.; Lima: Editorial Peisa. Décima edición.

RAPOPORT, A., 1969 - House form and culture; London: University College. Foundations of Cultural Geography Series.

RAVINES, R., 1985 - Inventario de Monumentos Arqueológicos del Perú: Lima Metropolitana (primera aproximación), 105p.; Lima: Municipalidad de Lima Metropolitana. Instituto Nacional de Cultura, INC.

RAMIREZ HORTON, S., 1996 - The world upside down. Cross cultural contact and conflict in the sixteenth century Peru, 234p.; Stanford: Stanford University Press.

ROSTWOROWSKI, DE DIEZ CANSECO, M., 1978 - Señoríos Indígenas de Lima y Canta, 280p.; Lima: Instituto de Estudios Peruanos,

ROSTWOROWSKI, DE DIEZCANSECO, M., 1981 - Recursos Naturales Renovables y Pesca, Siglos XVI y XVII, 180p.; Lima: Instituto de Estudios Peruanos.

ROSTWOROWSKI, DE DIEZ CANSECO, M., 1989 - Costa Peruana Prehispánica, 318p.; Lima: Instituto de Estudios Peruanos.

SALOMON, F., 1995 - The beautiful grandparents: andean ancestor shrines and mortuary ritual as seen through colonial records. In: Tombs for the living: Andean mortuary practices (Tom Dillehay, ed.): 315-353; Washington D.C.: Dumbarton Oaks Research Library and Collection.

SHIMADA, I., 1994 - Pampa Grande and the Mochica Culture, 323p.; Austin: University of Texas Press.

TOPIC, J., 1980 - Excavaciones en los barrios populares de Chan Chan. In: Chan Chan, Metrópoli Chimú:267-282; Lima: Instituto de Estudios Peruanos-Instituto de Investigación Tecnológica Industrial y de Normas Técnicas.

TOSSO, W., 1997 - Proyecto de Evaluación Arqueológica Laguna Azul. Zona Arqueológica de Monterrey. Distrito de Ate; Lima: Informe presentado al INC.

TRIGGER, B., 1990 - Monumental Architecture: a thermodynamic explanation of symbolic behaviour. World Archaeology, 22(2): 119-132.

UHLE, M., 1903 - Pachacamac. The University Museum. University of Pennsylvania. A reprint of the 1903 edition by Max Uhle. Izumi Shimada ed., 1991.

UNIVERSIDAD NACIONAL DE INGENIERÍA-FUNDACIÓN FORD, 1994 - Inventario del Patrimonio Monumental Inmueble de Lima. Valles de Chillón, Rímac y Lurín, Lima: Facultad de Urbanismo Arquitectura y Artes (UNI)-Fundación FORD. Arq. Víctor Pimentel y Arql. Duccio Bonavia, ed. 
URTON, G. \& BREZINE, C., Ms - Summation and partition in a Khipu archive from the palace of Puruchuco, central coast of Peru, 50p.

VETTER, L., 2004 - Las piezas de metal del museo de sitio Arturo Jiménez Borja-Puruchuco. In: Puruchuco y la Sociedad de Lima: Un homenaje a Arturo Jiménez Borja (Luis Felipe Villacorta, Luisa Vetter \& Carlos Ausejo, eds.): 119-139; Lima: CONCYTEC, Compañía de Minas Buenaventura y Diagnósticos Gammagráficos.

VILLACORTA, L. F., 2001 - Arquitectura monumental: forma, función y poder. Los asentamientos del valle medio bajo del Rímac (periodos Intermedio Tardío y Horizonte Tardío), 2 tomos. Tesis para optar el título de Licenciado en Arqueología. Facultad de Letras y Ciencias Humanas; Lima: Pontificia Universidad Católica del Perú.

VILLACORTA, L. F., 2004 - Puruchuco, medio siglo después. In: Puruchuco y la sociedad de Lima: Un homenaje a Arturo Jiménez Borja (Luis Felipe Villacorta, Luisa Vetter \& Carlos Ausejo, eds.); Lima: CONCYTEC, Compañía de Minas Buenaventura y Diagnósticos Gammagráficos.

WAKEHAM DASSO, R., 1978 - Puruchuco. Investigación Arquitectónica. In: Actas del III Congreso Peruano El Hombre y la Cultura Andina. Tomo II (Ramiro Matos, ed.): 451481; Lima.

WASON, P., 1996 - The Archaeology of Rank, 208p.; Cambridge: Cambridge University Press.

ZUIDEMA, T., 1989-Reyes y Guerreros: Ensayos de Cultura Andina, 563p.; Lima: Fomciencias. Grandes Estudios Andinos. 